\title{
Intervención paliativa de las limitaciones funcionales en la masticación y la deglución de las personas con cáncer de cavidad oral avanzado
}

\author{
Palliative intervention of functional limitations in chewing and swallowing in people with \\ advanced oral cavity cancer
}

Filiación:

${ }^{1}$ Facultad de Odontología, Universidad de Costa Rica, San José, Costa Rica. ${ }^{2}$ Consultorio odontológico privado, San José, Costa Rica.

${ }^{3}$ Instituto Costarricense de Investigación y Enseñanza en Nutrición y Salud (INCIENSA),

Cartago, Costa Rica.

${ }^{4}$ Instituto Investigación y Desarrollo Científico Académico (IIDCA), Universidad Santa Paula, San José, Costa Rica.

Correspondencia: $\square$ Juan Bautista Barahona Cubillo, correo electrónico:

juan.barahona@ucr.ac.cr

Forma de citar: Barahona Cubillo JB, Barquero-Arce M, Roselló-Araya M. Intervención paliativa de las limitaciones funcionales en la masticación y la deglución de las personas con cáncer de cavidad oral avanzado. Rev Ter. 2022;16(1): 24-49.

Financiamiento:

Ninguno

Conflictos de Interés:

Ninguno

Abreviaturas:

ácido desoxirribonucleico AINES, antinflamatorios no esteroideos; ATM, articulación temporomandibular;

CCE, carcinoma de células escamosas; CCO, cáncer de cavidad oral; $\mathrm{CP}$, cuidados paliativos; EVA, escala visual análoga; $\mathrm{NCl}$, National Cancer Institute (por sus siglas en inglés); OMS; Organización Mundial de la Salud; ORN, osteorradionecrosis; SNC, sistema nervioso central.

Fecha de envío: 17 de octubre del 2021.

Fecha de aceptación: 27 de diciembre del 2021.
Juan Bautista Barahona-Cubillo $\square$, Milagro Barquero-Arce², Marlene Roselló-Araya ${ }^{3-4}$.

\section{Resumen}

Introducción: el cáncer de cavidad oral se caracteriza por tener alta prevalencia, una tasa de supervivencia baja y representa un problema de salud pública. La masticación y la deglución pueden afectarse, como consecuencia de las lesiones primarias del cáncer o por los efectos adversos del tratamiento. Objetivo: determinar las limitaciones funcionales en la masticación y deglución en personas con cáncer de cavidad oral avanzado desde un enfoque interdisciplinario para una intervención odontológica paliativa. Metodología: artículo de revisión bibliográfica narrativa que incluyó 45 artículos en inglés, español y portugués, publicados del año 2013 en adelante. La población de interés fueron las personas adultas con cáncer oral avanzado que presenten limitaciones en la masticación y deglución en condiciones de Cuidados Paliativos. Se excluyeron resúmenes o comunicaciones de congresos y editoriales. Resultados: la masticación y la deglución pueden presentar limitaciones en su función que requieren una intervención paliativa desde el enfoque odontológico. Dentro de las intervenciones se pueden citar el control del trismus, la protección de las piezas dentales y sus tejidos de soporte, el cuidado de las prótesis dentales, el control del dolor y de las infecciones, la prevención y tratamiento de la osteorradionecrosis, la atención de la xerostomía, la intervención de la mucositis oral, la reconstrucción quirúrgica de estructuras anatómicas perdidas, la utilización de prótesis maxilofaciales y el control de edema. Conclusión: la odontología tiene un rol relevante en la intervención paliativa de las personas con cáncer de cavidad oral avanzado con limitaciones de la masticación y deglución al proporcionar un cuidado total y activo de la boca, en el que el alivio del dolor y el mantenimiento de las piezas dentales son una prioridad.

Palabras clave: cuidados paliativos, cáncer oral, masticación, deglución.

\section{Abstract}

Introduction: oral cavity cancer is characterized by having a high prevalence, a low survival rate and represents a public health problem. Chewing and swallowing can be 
impaired, as a consequence of primary cancer lesions or adverse effects of treatment. Objective: to determine the functional limitations in chewing and swallowing in people with advanced oral cavity cancer from an interdisciplinary approach for a palliative dental intervention. Methodology: narrative review article that included 45 articles in English, Spanish and Portuguese, published from 2013 onwards. The population of interest were adults with advanced oral cancer who present limitations in chewing and swallowing under Palliative Care conditions. Abstracts or conference papers and editorials were excluded. Results: chewing and swallowing may present limitations in their function that require palliative intervention from the dental approach. Among the interventions can be mentioned the control of trismus, the protection of the teeth and their supporting tissues, the care of dental prostheses, the control of pain and infections, the prevention and treatment of osteoradionecrosis, care of xerostomia, the intervention of oral mucositis, the surgical reconstruction of lost anatomical structures, the use of maxillofacial prostheses and the control of edema. Conclusion: dentistry has a relevant role in the palliative intervention of people with advanced oral cavity cancer with limitations of chewing and swallowing by providing a total and active care of the mouth, in which pain relief and tooth maintenance dental are a priority.

Keywords: palliative care, oral cancer, chewing, swallowing.

\section{Introducción}

El cáncer de cavidad oral (CCO) es una causa importante de morbilidad y mortalidad, el cual está en aumento en la mayoría de los países. Se presenta mayormente en personas mayores de 50 años y es más común en hombres que en mujeres $^{1,2}$. Se caracteriza por tener una alta incidencia, prevalencia y una tasa de supervivencia baja $^{3}$ y representa un problema de salud pública ${ }^{4}$. Tomando en cuenta los cánceres de la cavidad oral y la faringe como un conjunto, se estima que en 2012 se produjeron 529.000 casos nuevos en todo el mundo y se presentaron 292.000 muertes $^{5}$.

La patología provoca cambios estructurales en la boca que repercuten negativamente en funciones como la masticación y la deglución, las cuales son fundamentales para que se lleve a cabo una alimentación adecuada. Además, las terapias contra el CCO pueden provocar complicaciones, generalmente relacionadas a los efectos tóxicos de la radioterapia y la quimioterapia ${ }^{6}$. Estas complicaciones se asocian con una pérdida significativa de la función de la cavidad oral y, además, pueden provocar desfiguración facial que conduce a una disminución de la calidad de vida y a resultados psicosociales no deseados ${ }^{5}$.

La intervención paliativa proporciona una atención especializada en personas con enfermedades que amenazan la vida, enfocándose en brindar alivio de los síntomas y del estrés de una enfermedad grave, independientemente del diagnóstico y se direcciona así a mejorar la calidad de vida tanto de la persona enferma como de su grupo cuidador. La introducción de estos cuidados tempranamente en el proceso de la enfermedad permite a los profesionales en ciencias de la salud detectar los cambios sutiles que ocurren y ayudar al paciente y su familia a adaptarse a la progresión de la enfermedad, redefinir los objetivos de la atención y replantear la expectativa de vida ${ }^{7}$.

El objetivo de este artículo es determinar las limitaciones funcionales en la masticación y deglución en personas con CCO avanzado desde un enfoque interdisciplinario para una intervención odontológica paliativa. 


\section{Materiales y métodos}

Se desarrolló un estudio descriptivo de revisión bibliográfica narrativa. Las bases de datos consultadas fueron: Clinical Key, DOAJ, Ebsco Host, PubMed, Science Direct, SciELO. Se realizó, además, búsqueda en la Revista Terapéutica de la Universidad Santa Paula y en el Journal Annals of Palliative Medicine. Las palabras clave utilizadas fueron cuidados paliativos, cáncer oral, limitaciones funcionales, masticación y deglución. La población de interés fueron las personas adultas con cáncer oral avanzado que presenten limitaciones en la masticación y deglución en condiciones de cuidados paliativos. El periodo de estudio fue de 2013 en adelante y se tomaron en cuenta para los resultados 45 artículos en inglés, español y portugués, que corresponden a los 5 niveles de evidencia científica según la jerarquización de Sackett, siendo el quinto nivel el mayor con un $60 \%$ de las publicaciones, le sigue el IV nivel con $17,78 \%$, el III nivel con $15,55 \%$, el I nivel con $4,45 \%$ y el II nivel con $2,22 \%$. Se excluyeron resúmenes o comunicaciones de congresos y editoriales.

\section{Discusión de resultados}

El CCO tiene asociados dentro sus consecuencias una serie de cambios funcionales, que se presentan tanto por los efectos de la enfermedad en sus distintas presentaciones, como las lesiones endofíticas, exofíticas o metastásicas; así también como consecuencia del tratamiento oncológico de cirugía, quimioterapia y radioterapia ${ }^{8}$.

Los mecanismos de la masticación y la deglución pueden presentar limitaciones en su funcionalidad producto de la aparición del CCO, así como de su terapéutica que también genera reacciones adversas y complicaciones que influyen negativamente Existen distintas condiciones clínicas, descritas en las tablas 1 y 2 , que podrían desencadenar en estas afectaciones.

El CCO y su intervención están asociados con un trastorno emocional y psicológico. Esto afecta la calidad de vida de los pacientes y tiene impacto no solo en ellos, sino también en su entorno. Los factores funcionales, estéticos, emocionales y sociales determinan la calidad de vida y deben recibir la atención en la planificación de los Cuidados Paliativos $(\mathrm{CP})^{27}$.

La calidad de vida puede variar mucho en pacientes con $\mathrm{CCO}$ con resultados funcionales similares. Esto se debe esencialmente a los parámetros psicológicos ${ }^{28}$, al sentimiento de pérdida de identidad y de propósito $^{29}$, al estado socioeconómico ${ }^{30}$, a la insatisfacción de la apariencia y a la preocupación por la imagen corporal ${ }^{31}$, que tienen impacto en la percepción de los pacientes sobre su estado de salud y calidad de vida ${ }^{28}$. Por ejemplo, una persona con problemas emocionales con frecuencia descuida su salud bucal ${ }^{32}$.

A la luz de su diagnóstico, las personas enfermas pueden tener mejoría en su situación de dolor total (físico, emocional, social y espiritual) en que se encuentran, por medio de la fuerza interior, las creencias espirituales o las interacciones con otros individuos, en una progresión mediante el cuidado personal biopsicosocial y espiritual para así reducir el sufrimiento y mejorar la calidad de vida ${ }^{33}$.

\section{Intervención paliativa de las limitaciones}

\section{funcionales en la masticación y deglución del} cáncer de cavidad oral avanzado

Si bien puede haber una variedad de opciones para la atención en la práctica clínica diaria, puede haber menos opciones para la intervención en pacientes con cáncer avanzado. La intervención 
paliativa depende de varios factores, que incluyen la naturaleza del problema y del tratamiento y la disponibilidad de este, el estado general de salud de la persona enferma, en particular, los deseos de esa persona ${ }^{34}$.

Los profesionales en odontología tienen un papel importante en la atención de estas personas al proporcionar un cuidado total y activo de la cavidad oral. El alivio del dolor y el mantenimiento de las piezas dentales deben ser una prioridad. Las intervenciones de rutina realizadas por un odontólogo en el equipo de CP, que incluyen diagnóstico de afecciones dentales, cuidado de la higiene bucal, atención de la caries dental, tratamiento de problemas periodontales, satisfacción de necesidades protésicas e instrucciones para la hidratación adecuada de la mucosa oral, conducen a paliar las limitaciones funcionales en las personas con $\mathrm{CCO}^{35}$.

\section{Intervención del trismus y de desórdenes en la articulación temporomandibular}

Es necesario que se realice una evaluación de la articulación temporomandibular (ATM), ya que las disfunciones temporomandibulares contribuyen en la "reducción de la fuerza de la masticación debido al espasmo muscular y a las desventajas biomecánicas concurrentes"36.

En el trismus hay una restricción y limitación del rango de movimiento de la boca, generando implicaciones significativas en la salud en general, bucodental y en las actividades cotidianas ${ }^{37}$. El riesgo de desarrollar trismus siempre debe considerarse durante la fase de planificación previa a la radioterapia. La dosis de radiación al aparato masticatorio necesita minimizarse tanto como sea posible sin comprometer el control del tumor regional. El trismus inducido por radioterapia es difícil de controlar ${ }^{6}$.

En un estudio transversal en 89 personas en estado postoperatorio de CCO, concluyeron que una apertura de boca de menos de $35 \mathrm{~mm}$ (independientemente del estado dental) fue consistente con la pérdida del estado funcional de la masticación ${ }^{38}$. Para prevenir las limitaciones de apertura es importante comenzar ejercicios de estiramiento de la mandíbula antes de que se establezca el trismus, como un enfoque preventivo efectivo ${ }^{6}$. Estos ejercicios deben fomentarse durante la radioterapia para mantener la máxima apertura bucal y prevenir la fibrosis muscular ${ }^{39}$. El uso continuo de los ejercicios de estiramiento pasivos durante el período postradioterapia previene la contracción muscular tónica y mejora la apertura bucal ${ }^{6}$.

La base del tratamiento del trismus es la fisioterapia que utiliza ejercicios activos de rango de movimiento, técnicas de retención, relajación, estiramiento manual y distracción articular. Debido a la naturaleza refractaria del trismus asociado al tratamiento del cáncer, se han investigado otras técnicas y tratamientos. La pentoxifilina, que afecta la producción de citocinas fibrogénicas, puede mejorar el trismus establecido, sin embargo, no hay ensayos aleatorios grandes disponibles ${ }^{38,40}$.

Existen varios dispositivos disponibles para ayudar en el estiramiento de los músculos contraídos y los tejidos blandos fibróticos ${ }^{38}$. Uno de los dispositivos es el TheraBite $®$, el cual es un controlado por la persona con 2 boquillas que se insertan entre las arcadas superior e inferior. Cuando se aplica presión en las manijas, las boquillas se abren, lo que indirectamente ejerce presión sobre los maxilares en la dirección opuesta. Cuando se usa durante un período largo a intervalos regulares, se han encontrado mejores resultados ${ }^{40}$. 


\section{Tabla 1. Condiciones clínicas relacionadas al cáncer de cavidad oral que propician limitaciones masticatorias}

\begin{tabular}{|c|c|c|c|}
\hline Condición clínica & Características & Efecto & $\begin{array}{l}\text { Autores que lo } \\
\text { describen }\end{array}$ \\
\hline $\begin{array}{l}\text { Lesiones exofíticas } \\
\text { (masas o bultos) }\end{array}$ & $\begin{array}{l}\text { Ubicación en bordes laterales de la lengua, } \\
\text { labios o carrillos. } \\
\text { Propensas al sangrado. }\end{array}$ & $\begin{array}{l}\text { Interfieren en la trituración de } \\
\text { alimentos. }\end{array}$ & Silva D, $2010^{9}$ \\
\hline Dolor & $\begin{array}{l}\text { Presente en tejido blando, muscular, óseo y } \\
\text { nervioso. } \\
\text { Estadios avanzados del carcinoma de } \\
\text { células escamosas (CCE), cáncer oral más } \\
\text { común. }\end{array}$ & $\begin{array}{l}\text { Limita los movimientos de } \\
\text { apertura, cierre y lateralidad de la } \\
\text { mandíbula. }\end{array}$ & $\begin{array}{l}\text { Rhodus NL et al., } \\
2013^{10} \\
\text { Moreno OL et al., } \\
2007^{11} \\
\text { Álvarez-Martínez E et } \\
\text { al., } 2010^{12}\end{array}$ \\
\hline Linfadenopatía palpable & $\begin{array}{l}\text { Afectación por metástasis de nódulos } \\
\text { linfáticos regionales que toman un gran } \\
\text { tamaño. }\end{array}$ & $\begin{array}{l}\text { Afectación en los movimientos } \\
\text { realizados por la mandíbula. }\end{array}$ & $\begin{array}{l}\text { Rhodus NL et al., } \\
2013^{10} \\
\text { Saloura V et al., } 2013^{13}\end{array}$ \\
\hline Trismus & $\begin{array}{l}\text { Contracción y fibrosis en músculos } \\
\text { masticatorios por radioterapia. } \\
\text { Contracción de cicatriz postquirúrgica. }\end{array}$ & $\begin{array}{l}\text { Reducción en la apertura bucal. } \\
\text { Se define como una apertura } \\
\text { bucal de } 35 \mathrm{~mm} \text { o menos. }\end{array}$ & $\begin{array}{l}\text { Villa A et al., } 2018^{6} \\
\text { Caputo JB et al., } 2012^{14} \\
\text { Kolokythas A et al., } \\
2010^{15} \\
\text { Dijkstra P et al., } 2010^{16} \\
\text { Moon EH et al., } 2017^{17}\end{array}$ \\
\hline $\begin{array}{l}\text { Movilidad y pérdida de } \\
\text { piezas dentales }\end{array}$ & $\begin{array}{l}\text { CCO presente en gíngiva. } \\
\text { Pérdida de tejidos de soporte del diente } \\
\text { (gíngiva y hueso alveolar). }\end{array}$ & $\begin{array}{l}\text { Restricción respecto a la } \\
\text { consistencia de alimentos que se } \\
\text { pueden masticar. } \\
\text { Se afecta la fisiología de la } \\
\text { masticación. }\end{array}$ & $\begin{array}{l}\text { Silva D, } 2010^{9} \\
\text { Caputo JB et al., } 2012^{14}\end{array}$ \\
\hline $\begin{array}{l}\text { Resección de huesos } \\
\text { maxilares }\end{array}$ & $\begin{array}{l}\text { Pérdida total de bloques óseos incluyendo } \\
\text { el hueso alveolar. }\end{array}$ & $\begin{array}{l}\text { Afecta rendimiento masticatorio y } \\
\text { fuerza de mordida. }\end{array}$ & $\begin{array}{l}\text { Caputo JB et al., } 2012^{14} \\
\text { Kolokythas A et al., } \\
2010^{15}\end{array}$ \\
\hline $\begin{array}{l}\text { Osteorradionecrosis } \\
(\text { ORN) }\end{array}$ & $\begin{array}{l}\text { Se presenta clínicamente como una } \\
\text { exposición ósea dolorosa o indolora sin } \\
\text { cicatrización dentro de un campo irradiado, } \\
\text { que ha persistido sin cicatrizar por más de } \\
8 \text { semanas. }\end{array}$ & $\begin{array}{l}\text { Hueso necrótico expuesto que } \\
\text { retiene alimentos y puede afectar } \\
\text { tejido periodontal de piezas } \\
\text { adyacentes a la lesión. }\end{array}$ & $\begin{array}{l}\text { Villa A et al., } 2018^{6} \\
\text { Moon EH et al., } 2017^{17} \\
\text { Spijkervet F et al., } \\
2010^{18}\end{array}$ \\
\hline Mucositis & $\begin{array}{l}\text { Ulceraciones producto del daño o apoptosis } \\
\text { a las células madre basales del epitelio de } \\
\text { tejidos bucales, inducidas por radioterapia o } \\
\text { quimioterapia. }\end{array}$ & $\begin{array}{l}\text { Incapacidad para realizar la } \\
\text { masticación normalmente. }\end{array}$ & $\begin{array}{l}\text { Villa A et al., } 2018^{6} \\
\text { Sonis S et al., } 2010^{19}\end{array}$ \\
\hline Infecciones & $\begin{array}{l}\text { Infección de tejidos duros y blandos por } \\
\text { la disbiosis en el microbiota oral (virus, } \\
\text { bacterias y hongos). }\end{array}$ & $\begin{array}{l}\text { Limitación en la masticación por } \\
\text { la inflamación y el dolor asociada } \\
\text { a la infección. }\end{array}$ & Villa A et al., $2018^{6}$ \\
\hline $\begin{array}{l}\text { Daño en glándulas } \\
\text { salivales mayores y } \\
\text { menores }\end{array}$ & $\begin{array}{l}\text { Hiposalivación. } \\
\text { Resequedad bucal. } \\
\text { Aumento en la viscosidad de la saliva. }\end{array}$ & $\begin{array}{l}\text { Afecta la formación del bolo } \\
\text { alimenticio. } \\
\text { Ambiente propicio de caries } \\
\text { dental y periodontitis. }\end{array}$ & Caputo JB et al., $2012^{14}$ \\
\hline
\end{tabular}

Fuente: elaboración propia, basada en las referencias ${ }^{6,9-19 .}$ 


\section{Tabla 2. Condiciones clínicas relacionadas al cáncer de cavidad oral que propician limitaciones en la deglución}

\begin{tabular}{|c|c|c|c|}
\hline Condición clínica & Características & Efecto & Autores que lo describen \\
\hline $\begin{array}{l}\text { Alteraciones de tipo } \\
\text { estructural -anatómico por } \\
\text { lesiones primarias }\end{array}$ & $\begin{array}{l}\text { Afectación en el tejido muscular y } \\
\text { nervioso. }\end{array}$ & $\begin{array}{l}\text { Limitación en el mecanismo } \\
\text { deglutorio. }\end{array}$ & Campora H et al., $2012^{20}$ \\
\hline Hiposalivación & Xerostomía & $\begin{array}{l}\text { Dificultad para la formación } \\
\text { de bolo alimenticio y por } \\
\text { consiguiente produciendo } \\
\text { disfagia. }\end{array}$ & Nemeth D et al., $2017^{21}$ \\
\hline $\begin{array}{l}\text { La lengua que ha } \\
\text { sido sometida a una } \\
\text { intervención quirúrgica }\end{array}$ & $\begin{array}{l}\text { Rango de movilidad de la lengua } \\
\text { disminuido. }\end{array}$ & $\begin{array}{l}\text { Dinámica deglutoria en la fase } \\
\text { oral y de transporte alteradas. }\end{array}$ & $\begin{array}{l}\text { Galarza-lbarrondo I et al., } \\
2014^{22} \\
\text { Zuydam AC et al., } 2005^{23} \\
\text { Halczy-Kowalik L et al., } \\
2015^{24}\end{array}$ \\
\hline Mucositis & $\begin{array}{l}\text { Irritación y ulceraciones de los tejidos } \\
\text { blandos. }\end{array}$ & $\begin{array}{l}\text { Intolerancia para deglutir } \\
\text { alimentos. }\end{array}$ & $\begin{array}{l}\text { Sonis S et al., } 2010^{19} \\
\text { Jimenez et al., } 2006^{25}\end{array}$ \\
\hline $\begin{array}{l}\text { Mandíbula discontinua por } \\
\text { cirugía de resección }\end{array}$ & $\begin{array}{l}\text { Capacidad reducida de movimientos } \\
\text { mandibulares. }\end{array}$ & $\begin{array}{l}\text { Retención de alimentos en la } \\
\text { boca, perjudicando la deglución } \\
\text { funcional. }\end{array}$ & $\begin{array}{l}\text { Halczy-Kowalik L et al., } \\
2015^{24} \\
\text { Chi et al, } 2015^{26}\end{array}$ \\
\hline $\begin{array}{l}\text { Pérdida de paladar } \\
\text { producto de cirugía }\end{array}$ & $\begin{array}{l}\text { Perdida de tejido esencial para el } \\
\text { cierre durante la deglución. }\end{array}$ & Disfagia por pérdida estructural. & $\begin{array}{l}\text { Halczy-Kowalik L et al., } \\
2015^{24}\end{array}$ \\
\hline $\begin{array}{l}\text { Edema y fibrosis por } \\
\text { radioterapia }\end{array}$ & $\begin{array}{l}\text { Trastornos neuromusculares de los } \\
\text { tejidos. }\end{array}$ & $\begin{array}{l}\text { Mayor retención faríngea de } \\
\text { alimentos. }\end{array}$ & $\begin{array}{l}\text { Nemeth D et al., } 2017^{21} \\
\text { Halczy-Kowalik L et al., } \\
2015^{24}\end{array}$ \\
\hline
\end{tabular}

Fuente: elaboración propia, basado en referencias ${ }^{19-26 .}$

Mejorar el trismus con cirugía de colgajo y la utilización de inyecciones de toxina botulínica, son otros enfoques de tratamiento que se están explorando y han tenido resultados mixtos ${ }^{6}$. En la Tabla 3 se resumen los tipos de intervención del trismus.

\section{Cuidado de las piezas dentales}

La valoración de las piezas dentales y de la oclusión por el profesional en odontología es importante por su relación con la fuerza de la mordida. La presencia de la caries dental tiende a asociarse con una fuerza de la mordida más débil, debido a la aparición de sistemas reflejos ${ }^{36}$.
Cualquier diente en el campo irradiado durante la terapia oral contra el cáncer está en riesgo de desarrollar caries por radiación, que puede progresar rápidamente a enfermedad periapical, asimismo, la quimioterapia puede exacerbar cualquier trastorno dental subclínico. Además de los efectos directos de la radiación en los dientes, una disminución en el flujo salival y el cambio de la microbiota oral a un tipo más cariogénico son factores adicionales que promueven la caries dental avanzada ${ }^{6}$.

Parte de los esfuerzos deben centrarse en preservar el mayor número de piezas dentales posibles y realizar las restauraciones dentales 
necesarias, pues se ha reportado una correlación positiva entre el número de dientes presentes y la fuerza de mordida, y que esta decreció el $56 \%$ cuando los sujetos perdieron tres o más dientes posteriores. También, se ha reportado la importancia del número de contactos oclusales, pues cuando el área de contacto oclusal se duplica, la fuerza de mordida incrementa del $30 \%$ al $100 \%$, por una mejor distribución de la fuerza, logrando así una mordida más potente ${ }^{36}$.

Una recomendación es realizar evaluaciones dentales, radiográficas completas y proporcionar tratamientos dentales urgentes antes de que comience la terapia oral contra el cáncer. Sin embargo, el momento de esta terapia y las condiciones del paciente a menudo no son óptimas para permitir que se completen. Para prevenir o detener la progresión de la caries, es necesaria la aplicación de fluoruros, en gel o barniz, porque propician la remineralización dental ${ }^{6}$.

El mantenimiento de una buena higiene bucal es importante para conservar la calidad de vida en personas con cáncer. Por esta razón se debe instruir respecto a las medidas adecuadas para el cuidado de las piezas dentales y hacer extensiva esta instrucción a familiares y cuidadores ${ }^{34}$. En la Tabla 4 , se describen las medidas de higiene bucodental que son necesarias de aplicar en personas con CCO avanzado.

Es necesario realizar un adecuado control de los tejidos de soporte periodontal, mediante la prevención y el tratamiento de la periodontitis, pues las cargas producidas por los músculos masticatorios son controladas por mecanorreceptores del ligamento periodontal y la adaptación de la fuerza de mordida a la dureza de la comida es dependiente de la información que envían estos mecanorreceptores hacia el sistema nervioso central (SNC). En consecuencia, la disminución del soporte periodontal decrece el nivel del umbral de los mecanorreceptores y esta condición puede generar cambios en la masticación ${ }^{36}$.

\section{Utilización de prótesis dentales}

Las personas con CCO pueden estar utilizando prótesis dentales o también requerirlas para poder realizar la función masticatoria adecuadamente. La higiene de las prótesis debe llevarse a cabo regularmente e incorporarse como una rutina diaria del cuidado bucal, debe hacerse al menos una vez al día (preferiblemente por la noche), idealmente se puede realizar limpieza después de cada comida. Todas las prótesis dentales necesitan limpiarse fuera de la cavidad oral; así como los tejidos blandos de la boca por separado ${ }^{34}$.

Las prótesis se deben limpiar primero con agua para eliminar los restos de alimentos y luego frotar bien con un cepillo de dientes grande, uno para prótesis dental o uno de uñas personal para desalojar el biofilm dental restante. Existen productos comerciales disponibles para la limpieza de las prótesis, pero el agua y el jabón, o el agua sola, generalmente son satisfactorios ${ }^{34,41}$.

No se debe usar crema dental para limpiar las prótesis, por ser abrasiva y puede dañar sus superficies. Es necesario enjuagar bien la dentadura antes de volver a colocarla en la boca del paciente. El cálculo puede formarse en las superficies lisas de una prótesis como resultado de la deposición de calcio de la saliva. El cálculo puede irritar la mucosa oral subyacente y debe eliminarse profesionalmente de manera pronta. Además, para mantener una mucosa oral saludable, es aconsejable dejar las prótesis fuera de la boca durante la noche ${ }^{34}$. 
Tabla 3. Intervención terapéutica del trismus en personas con cáncer oral

\begin{tabular}{|c|c|c|}
\hline Tratamiento & Objetivos & Descripción \\
\hline Terapia Física & $\begin{array}{l}\text { - } \text { Eliminar el edema. } \\
\text { - } \text { Propiciar la liberación y estiramiento del } \\
\text { - } \text { Aumentar el rango de movilidad de las } \\
\text { articulaciones. } \\
\text { - Restaurar la eficacia circulatoria. } \\
\text { - Aumentar la fuerza muscular. } \\
\text { - Mantener la destreza muscular }\end{array}$ & $\begin{array}{l}\text { Los ejercicios propuestos: } \\
\text { - Ejercicios con movimiento activo (abrir y cerrar la } \\
\text { boca, y movimientos laterales de la mandíbula, } \\
\text { durante } 5 \text { minutos cada } 3 \text { a } 4 \text { horas. } \\
\text { - Ejercicios con movimiento pasivo, ayudado con } \\
\text { mecanismos externos. } \\
\text { - Liberación manual y relajación. } \\
\text { - La goma de mascar (sin azúcar) produce } \\
\text { movimiento lateral de la ATM. }\end{array}$ \\
\hline Terapia de calor & - Ayudar a aliviar la incomodidad del trismus. & $\begin{array}{l}\text { Consiste en aplicar toallas calientes y húmedas } \\
\text { en forma alterna en el área afectada por } \\
\text { aproximadamente } 20 \text { minutos cada hora. } \\
\text { Enjuagues bucales con solución salina tibia, se } \\
\text { agrega una cucharadita de sal a un vaso de agua } \\
\text { tibia( } 350 \mathrm{~mL} \text { ), esta solución se mantiene en la boca } \\
\text { del lado afectado (luego se escupe) }\end{array}$ \\
\hline $\begin{array}{l}\text { Terapia farmacológica } \\
\text { para control de dolor y la } \\
\text { inflamación }\end{array}$ & $\begin{array}{l}\text { - } \text { Generar analgesia. } \\
\text { - Disminuir la inflamación. } \\
\text { - Relajar los músculos de la masticación. }\end{array}$ & $\begin{array}{l}\text { Antiinflamatorios no esteroideos (AINES) } \\
\text { generalmente son adecuados para el control del dolor } \\
\text { asociado al trismus. } \\
\text { El uso de opioides puede ser necesario si el malestar } \\
\text { es severo. } \\
\text { Se pueden utilizar relajantes musculares, como las } \\
\text { benzodiacepinas, si es necesario. }\end{array}$ \\
\hline $\begin{array}{l}\text { Intervención } \\
\text { dispositivos de apertura } \\
\text { bucal }\end{array}$ & $\begin{array}{l}\text { - Mejorar el cumplimiento del ejercicio. } \\
\text { - Aumentar la eficacia terapéutica. }\end{array}$ & $\begin{array}{l}\text { Estas herramientas incluyen: } \\
\text { - Tapones de goma. } \\
\text { - Depresores de lengua (paletas de madera). } \\
\text { - Dispositivo TheraBite } \Re . \\
\text { - Abridores de mordedura dinámicos. }\end{array}$ \\
\hline Cirugía & $\begin{array}{l}\text { - Realizar la liberación del tejido fibroso. } \\
\text { - Aumentar el rango de movilidad de las } \\
\text { articulaciones. }\end{array}$ & $\begin{array}{l}\text { Aplica en los casos severos (<20 mm de distancia } \\
\text { interincisal), en los que no existe respuesta al } \\
\text { tratamiento conservador (alrededor de 20-30 } \\
\text { sesiones de terapia física). } \\
\text { Técnicas quirúrgicas descritas: } \\
\text { - La miotomía de los músculos masticatorios. } \\
\text { - Coronoidectomía. }\end{array}$ \\
\hline Toxina botulínica & - Disminuir la fibrosis de tejidos y el dolor. & $\begin{array}{l}\text { Inyección de toxina botulínica en los músculos } \\
\text { maseteros. }\end{array}$ \\
\hline Pentoxifilina & $\begin{array}{l}\text { - Disminuir la fibrosis muscular. } \\
\text { - Aumentar movimiento mandibular. }\end{array}$ & Interfiere en la inflamación mediada por citoquinas. \\
\hline
\end{tabular}




\section{Tabla 4. Medidas de higiene bucodental en personas con cáncer de cavidad oral avanzado}

\begin{tabular}{|c|c|}
\hline $\begin{array}{l}\text { Medidas de higiene } \\
\text { bucodental }\end{array}$ & Indicaciones \\
\hline Cepillado dental & $\begin{array}{l}\text { - Al menos dos veces al día. Mientras las condiciones de la persona enferma lo permitan, debe realizarse. } \\
\text { - Utilizar un cepillo de cabeza pequeña, que tenga cerdas de textura suave. Las cerdas ultrasuaves se } \\
\text { pueden usar para pacientes a quienes presentan dolor en la boca. } \\
\text { - Los cepillos eléctricos con acción de rotación y oscilación parecen ser mejores para eliminar el biofilm } \\
\text { dental que los cepillos de manuales en este grupo de personas y resulta una excelente alternativa. } \\
\text { - La vida útil recomendada de un cepillo de dientes es de aproximadamente } 3 \text { meses, pero debe } \\
\text { reemplazarse antes si los filamentos del cepillo se ablandan y se deforman. } \\
\text { - Los cepillos de dientes deben reemplazarse antes si el paciente está inmunosuprimido o recibe } \\
\text { - Ademaimioterapia. } \\
\text { algún tipo de infección oral. } \\
\text { - Una alternativa es utilizar gasas como medida de control mecánico del biofilm dental. }\end{array}$ \\
\hline Cremas dentales & $\begin{array}{l}\text { - Se debe usar crema dental que contenga al menos } 1000 \text { ppm de fluoruro. } \\
\text { - La mayoría de las cremas dentales contienen un agente espumante, que puede resultar problemático } \\
\text { para aquellos pacientes que tienen dificultad para tragar (y que corren el riesgo de aspiración). En estos } \\
\text { casos, se debe usar una alternativa no espumante. } \\
\text { - Si el paciente no tolera el uso de crema dental (debido a molestias orales), pueden usar agua durante } \\
\text { el cepillado. }\end{array}$ \\
\hline Limpieza interdental & $\begin{array}{l}\text { - Idealmente, alguna forma de limpieza interdental debe usarse a diario, aunque esto puede no ser factible } \\
\text { o apropiado para algunas personas. } \\
\text { - Los tipos de productos de limpieza disponibles incluyen hilo dental, cinta dental y cepillos interdentales. }\end{array}$ \\
\hline Control químico & $\begin{array}{l}\text { - Para algunas personas, el control mecánico del biofilm dental es extremadamente difícil debido a su nivel } \\
\text { de debilitamiento o a complicaciones por la patología oral. En tales casos, se puede considerar el control } \\
\text { químico del biofilm dental para el mantenimiento de la higiene bucal. } \\
\text { - La alternativa de primera elección es la clorhexidina. La molécula de clorhexidina tiene una carga positiva } \\
\text { en cada extremo, y se une fácilmente a sitios con carga negativa en la película de esmalte dental, las } \\
\text { células de la mucosa y las células bacterianas. Se libera lentamente de estas superficies, por lo que } \\
\text { mantiene su actividad antimicrobiana (una propiedad conocida como sustantividad). } \\
\text { - La clorhexidina se usa más comúnmente como enjuague bucal al } 0.12-0.2 \% \text { (10-15 ml dos veces al día), } \\
\text { aunque también está disponible como gel, crema dental y aerosol. } \\
\text { - No usar clorhexidina más de dos veces al día. } \\
\text { - El uso prolongado continuo de clorhexidina (más de } 2 \text { semanas) puede provocar pigmentaciones externas } \\
\text { en piezas dentales y dorso de la lengua; estas pueden ser removidas por el odontólogo. Se recomienda } \\
\text { periodos de descanso en su utilización. } \\
\text { - La clorhexidina no eliminará el cálculo dental; esto debe ser físicamente eliminado por un odontólogo. } \\
\text { Otra alternativa de agente antimicrobiano en el Cloruro de cetilpiridinio, un amonio cuaternario catiónico } \\
\text { contenido en enjuagues bucales, cremas dentales y en aerosol. }\end{array}$ \\
\hline
\end{tabular}

Fuente: elaboración propia basado en Davies ${ }^{34}$. 
En caso de que se decida por tratamientos protésicos durante la intervención paliativa, se prefiere restaurar las áreas edéntulas de corto alcance mediante prótesis parciales fijas con márgenes supragingivales, porque se reduce el contacto de la mucosa y la irritación. Las prótesis parciales removibles deben diseñarse con una cobertura de tejido blando mínima ${ }^{41}$.

La mayoría de los problemas con las prótesis dentales se relacionan con el mal ajuste de estas (por ejemplo, dolor, úlceras orales, alimentos que se retienen bajo la prótesis). Las infecciones fúngicas relacionadas con la prótesis también son comunes en personas con cáncer avanzado. Es importante que el odontólogo realice el ajuste de las prótesis tanto en la adaptación a los tejidos como en la oclusión para minimizar esas molestias ${ }^{34}$.

\section{Control del dolor bucomaxilofacial}

El dolor físico bucomaxilofacial debe controlarse considerando las cuatro dimensiones de factores contribuyentes o causales (físico, psicológico, social y espiritual) bajo el concepto de dolor total ${ }^{29}$. El dolor bucomaxilofacial, si no es controlado puede tener efectos limitantes en la calidad de vida de las personas con CCO avanzado ${ }^{6}$.

Existen varios métodos validados para establecer la severidad o intensidad del dolor, entre ellos las escalas numéricas del 0 a 10, las escalas verbales descriptivas -ninguno, leve, moderado, severo, insoportable- y las escalas visuales análogas (EVA) 0 a 3 leve, 4 a 6 moderado, 7 a 10 severo ${ }^{42}$.

El control farmacológico del dolor toma en consideración la escalera analgésica del dolor de la Organización Mundial de la Salud (OMS), recomendando el uso de antiinflamatorios no esteroideos (AINES) y paracetamol para el dolor más leve en el primer escalón, opioides débiles (tramadol, codeína) para el dolor moderado en el segundo escalón y opioides potentes (morfina, metadona, fentanilo) para el dolor intenso en el tercer escalón. Se pueden asociar fármacos adyuvantes en todas las etapas ${ }^{29}$.

La escalera analgésica de la OMS considera las necesidades individuales de la persona, de forma que sea importante seguir el esquema mencionado, pero con la flexibilidad según las características propias de la persona enferma y la respuesta al tratamiento. Por ejemplo, en ocasiones sucede que un enfermo esté con dolor importante (EVA > 6/10); en este caso se debe tratar de entrada con opioides del escalón 2 o $3^{42}$.

Al elegir medicamentos para controlar el dolor, es importante tener en cuenta la causa física de este. En el dolor nociceptivo, causado por una lesión tisular, la escalera analgésica se puede seguir paso a paso iniciando con paracetamol, AINES y opioides $^{29}$. El dolor neuropático, causado por daño a los nervios por compresión, lesión o toxicidad, es un síntoma frecuente. Las terapias contra el CCO producen efectos adversos secundarios como la neurotoxicidad. En el mecanismo de la neurotoxicidad inducida por la quimioterapia se ha implicado la inflamación, el estrés oxidativo y el daño al ácido desoxirribonucleico (ADN). La cirugía del CCO también puede alterar los nervios adyacentes en el campo quirúrgico y generar dolor neuropático. El tratamiento depende de la gravedad de los síntomas y se centra en el control del dolor con opioides como terapia de primera línea. Otros medicamentos coadyuvantes utilizados incluyen anticonvulsivos, antidepresivos, corticosteroides y anestésicos, así como suplementos nutricionales con ácido alfa lipoico, vitamina $\mathrm{E}$, eritropoyetina y acetil-L-carnitina ${ }^{6}$. 
Para el dolor causado por metástasis óseas, se debe considerar la utilización de bifosfonatos como medicamentos adyuvantes ${ }^{29}$. Para la intervención del dolor es importante tomar en cuenta las siguientes consideraciones:

- Utilización de forma preferentelavía oral, pero en caso de disfagia se pueden considerar vías alternativas de administración como la vía subcutánea.

- La dosis adecuada es aquella que suprima el dolor con los mínimos efectos secundarios.

- El régimen analgésico debe ser explicado cuidadosamente a la persona enferma y sus cuidadores; debe ser monitorizado en el tiempo, utilizando el medicamento acertado, por la vía, en la dosis e intervalo correctos ${ }^{42}$. Es importante tener en cuenta la posible presentación del dolor irruptivo, el cual se define como una "exacerbación transitoria o un brote de dolor moderado a severo que se produce sobre un fondo de dolor basal persistente y estable en una persona que recibe terapia crónica con opioides"29.

En el dolor irruptivo pueden distinguirse tres variedades: incidental (relacionado con actividades físicas), espontáneo y de final de dosis. Para el control del dolor irruptivo se recomienda usar un opioide oral de liberación inmediata en una dosis que corresponda aproximadamente al $10 \%$ de la dosis total diaria de morfina o su equivalente $e^{29,42}$.

Cerca de un $10 \%$ de las personas con dolor oncológico no responden bien a las medidas analgésicas estandarizadas y requieren de opciones de tratamiento de tipo intervencionista invasivo, que algunos han definido como "un cuarto escalón" añadido al esquema analgésico de la OMS. Algunos de estos procedimientos son los "bloqueos con agentes farmacológicos reversibles como anestésico local, corticoides, opioides u otros que se colocan por única vez en forma de bolos en algún tegumento, o bien, por medio de catéteres sobre nervios periféricos o autonómicos o cercano a la médula"42.

\section{Control de infecciones en cavidad oral}

La mielosupresión inducida por quimioterapia, el desarrollo de mucositis oral, la hiposalivación y la higiene bucal deficiente alteran la microbiota oral y aumentan la carga microbiana patógena, lo que hace que los enfermos sean susceptibles a infecciones bacterianas, virales y micóticas oportunistas. Los pacientes tienen un mayor riesgo de desarrollar infecciones odontogénicas si no reciben atención inmediata por alguna afectación dental o periodontal ${ }^{6}$.

Las personas inmunosuprimidas con enfermedad periodontal podrían desarrollar infecciones periodontales agudas como: gingivitis úlcero-necrotizante aguda y periodontitis úlceronecrotizante aguda. En estos casos, la intervención odontológica de higiene oral que reducen la colonización microbiana en las piezas dentales y el periodonto son necesarias. Entre las terapias tópicas están los enjuagatorios orales que contengan clorhexidina al 0,12\% y remoción mecánica del biofilm dental. En cuanto a la terapia sistémica, para cada caso específico, se debe elegir al antibiótico ${ }^{43}$.

La candidiasis es la infección oral más común, las personas pueden presentar una extensa capa pseudomembranosa o eritematosa en cualquiera de las superficies mucosas. Aunque la terapia antimicótica tópica puede ser eficaz para controlar la candidiasis oral en algunos pacientes, la terapia antimicótica sistémica a menudo es necesaria en casos de candidiasis oral diseminada y otras infecciones micóticas, como aspergilosis y mucormicosis $^{6}$. 
Para tratar infecciones localizadas en personas no inmunosuprimidos, se pueden utilizar antimicóticos como Nistatina $100.000 \mathrm{U} / \mathrm{ml}$ de (1 a 5 $\mathrm{ml}$ de suspensión 4 veces al día) o 1 a 2 comprimidos (200.000 U / pastilla) 4 veces al día, 7 a 14 días. Otra opción es Anfotericina B (1 comprimido de 10 mg 4 veces al día o $1 \mathrm{ml}$ de suspensión de100 mg / ml, 4 veces al día en un ciclo de 10 a 15 días). En infecciones generalizadas, persistentes o en personas inmunosuprimidas la primera línea de alternativa como antimicótico es Fluconazol 50-200 mg una vez al día (cápsula / suspensión oral) por de 7 a 14 días $^{34}$.

Asimismo, es muy probable que personas con CCO hayan estado expuestos al virus del herpes simple y esta condición puede reactivarse mediante mielosupresión inducida por quimioterapia, lo que hace que la persona desarrolle erupciones vesiculares y ulceraciones superficiales en la mucosa oral. El uso de terapia antiviral profiláctica con aciclovir a menudo se recomienda en pacientes que son seropositivos para el virus del herpes simple ${ }^{6}$.

\section{Prevención y tratamiento de la osteorradionecrósis (ORN)}

La ORN es una complicación poco común pero grave que puede causar dolor, formación de fístulas, deformidades faciales y fracturas patológicas en personas con CCO después del tratamiento oncológico. Algunas formas de ORN pueden curarse con un tratamiento conservador, pero las formas agresivas requieren desbridamientos repetidos e intervenciones quirúrgicas ${ }^{44}$.

Las personas con $\mathrm{CCO}$ que reciben dosis de radiación superiores a 50 Gy son muy susceptibles a la ORN ${ }^{6}$. El trauma está involucrado en la fisiopatología de la condición. Los dientes irreparables debido a caries, enfermedad periodontal o lesiones radiculares pueden causar infección ósea y progresar a ORN. La realización de exodoncias luego de la radioterapia, el abuso de alcohol y tabaco se identifican como factor de riesgo $0^{17,45}$.

La clave de la intervención odontológica es la prevención de la ORN ${ }^{45}$. En la Figura 1, se mencionan las medidas que se deben tomar en cuenta antes y después a la radioterapia.

En caso de que se presente la ORN, se debe intervenir lo más pronto posible, el tratamiento inicial será conservador. La evolución es impredecible, puede ocurrir desde una curación espontánea hasta una destrucción amplia. En casos severos puede ser necesaria la hemimandibulectomía y su posterior reconstrucción ${ }^{43}$.

El diagnóstico y el tratamiento de la ORN se basan en el historial y la presentación clínica, junto a pruebas radiológicas e histopatológicas. El tratamiento también se guía por el grado de exposición ósea y la gravedad de los síntomas. El tratamiento puede variar desde terapia conservadora con antibióticos e irrigación con solución salina y antisépticos tópicos como clorhexidina hasta una intervención más invasiva con desbridamiento quirúrgico y cirugía de colgajo ${ }^{6}$.

Entre los antibióticos la tetraciclina es la más indicada en dosis de $250 \mathrm{mg}$, vía oral 4 veces por día por 10 días y se puede combinar con $200 \mathrm{mg}$ de metronidazol 3 veces por día por su efecto en las bacterias anaeróbicas. En caso de ser necesaria una secuestrectomía se hará incisión sobre la cresta alveolar y se extirpará todo el hueso necrótico hasta que aparezcan zonas sangrantes ${ }^{43}$.

Varios protocolos han incorporado el uso de oxígeno hiperbárico como terapia complementaria antes y después del tratamiento quirúrgico de ORN para promover la curación ${ }^{6}$. Esta terapia aumenta 
la oxigenación del tejido irradiado, promueve la angiogénesis, afianza la repoblación deosteoblastos, mejora la función de los fibroblastos y tiene acción bacteriostática o bactericida. Esta terapia suele indicarse en forma de 20 a 30 sesiones de hora y media, una vez por día, en cámaras con oxígeno al $100 \%$ y de 2 a 2,5 atmósferas de presión ${ }^{43}$. Los informes sobre la eficacia de la terapia con oxígeno hiperbárico siguen siendo controvertidos y no se recomienda en personas con cáncer metastásico debido a su propiedad angiogénica ${ }^{6}$.

\section{Intervención paliativa de las limitaciones en la} deglución

La estrategia de intervención paliativa de las limitaciones en la deglución debe plantearse sobre la base de la evaluación clínica y la valoración de los estudios complementarios. Se busca compensar funcionalmente la dificultad que causa la disfagia para lograr una deglución segura y eficaz; intentando recuperar la función perdida, o bien, implementar un nuevo mecanismo que reemplace al anterior y permita una alimentación segura ${ }^{20}$.

La hiposalivación y la xerostomía como consecuencia de esta, así como la mucositis, las alteraciones estructurales por lesiones primaras o causadas por la intervención quirúrgica del cáncer, el edema y la fibrosis tisular son condiciones clínicas que necesitan una intervención paliativa para mejorar los mecanismos deglutorios.

\section{Medidas para prevenir la Osteorradionecrosis}

Educación sobre la higiene bucodental

Exodoncia de piezas dentales con bolsas de más de $6 \mathrm{~mm}$, movilidad grado II y afectación de furca

Evitar las prótesis removibles o fijas durante seis meses antes

Tratamiento de todas las caries dentales

Chequeos dentales semanales durante la radioterapia y cada tres meses postradioterapia posiblemente de por vida

Se pueden realizar tratamientos de endodoncia

Control de la boca seca

Tratamiento de todas las caries dentales

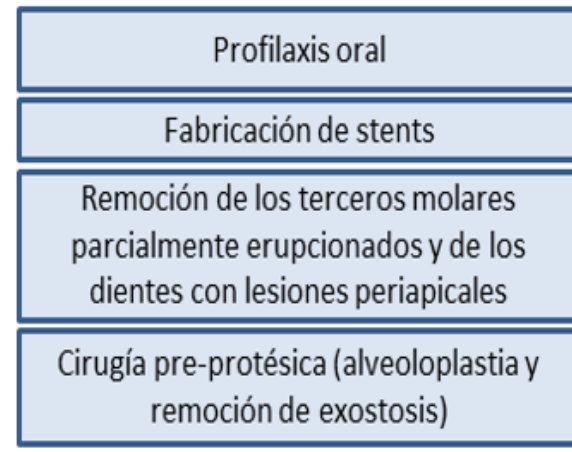

Evitar las prótesis removibles, coronas y puentes fijos durante seis meses

Mantener una dentición saludable, evitando exodoncias cuando sea posible

Post-Radioterapia

Enjuagues con clorhexidina y antibióticos durante cirugías orales

Terapia de oxigeno hiperbárico previo a cirugías orales

\section{Figura 1. Medidas para la prevención de la Osteorradionecrosis}

Fuente: elaboración propia basada en Brody et $\mathrm{al}^{39}$, Lanza Echeveste ${ }^{43}$ y Mulk et al $^{45}$ 


\section{Intervención de la xerostomía}

Se han utilizado con éxito enfoques tanto farmacológicos como no farmacológicos para aliviar los efectos de la reducción del flujo salival. Entre las alternativas no farmacológicas se encuentran los sustitutos de saliva, como la saliva artificial, ingesta frecuente de líquidos como el agua, chupar cubitos de hielo o paletas de helado sin azúcar y estimular la salivación por medio de la masticación de goma de mascar sin azúcar. Como alternativas farmacológicas, están sialagogos sistémicos agonistas colinérgicos eficaces para mejorar el flujo salival $^{6,39}$.

Muchas personas optan por usar la ingesta frecuente de agua y otros líquidos, el uso del agua no se asocia con efectos secundarios per se, aunque la polidipsia se asocia inevitablemente con poliuria ${ }^{34,39}$.

Respecto a la goma de mascar, es eficaz en el tratamiento de la xerostomía, en las personas con cáncer avanzado con disfunción de glándula salival inducida por fármacos, hay que tomar en cuenta algunos efectos secundarios como molestias en la mandíbula, dolor de cabeza y la ingestión inapropiada, que podría ocasionar obstrucción del tracto respiratorio, obstrucción gastrointestinal, por lo que su utilización debe ser muy controlada y supervisada en personas con problemas de masticación y deglución ${ }^{34}$.

\section{Saliva artificial}

El sustituto de saliva debe tener un $\mathrm{pH}$ neutro y propiedades antimicrobianas y remineralizantes, no ser irritante ni tóxico y tener sabor agradable. Los sustitutos de la saliva comercializados suelen estar basados en carboximetilcelulosa y ofrecen un alivio de corta duración ${ }^{32}$. Algunos productos comerciales sustitutos de saliva se presentan en la Tabla 5.

\section{Estimulantes sistémicos de la salivación}

Las medidas sistémicas consisten en la prescripción de colinérgicos como la pilocarpina y la cevimelina, que son efectivos cuando permanece la función residual de la glándula ${ }^{39}$.

La pilocarpina es un alcaloide natural estimulador de las glándulas exocrinas y su dosis recomendada de $5-10 \mathrm{mg}$ cada 8 horas. El flujo salival aumenta a los 15 minutos de la administración y mantiene su efectividad de una a dos horas. La pilocarpina se puede utilizar también en la presentación oftálmica al $2 \%(20 \mathrm{mg} / \mathrm{ml})$, aplicando 2-10 gotas en el piso de la boca 1-3 veces al día. Se ha informado que la pilocarpina es más eficaz que la saliva artificial en el tratamiento de la disfunción de glándula salival secundaria al tratamiento farmacológico y a la radioterapia ${ }^{34}$.

Estos agentes actúan como miméticos colinérgicos, pero tienen una variedad de efectos secundarios, como sudoración y aumento de las secreciones pulmonares. En la etapa final de la enfermedad, las secreciones pulmonares pueden producir sonidos durante la respiración, denominados "estertores pre mortem", que pueden resultar angustiantes para las personas con enfermedades en condiciones paliativas y su grupo cuidador ${ }^{32}$.

\section{Prevención y tratamiento de la mucositis}

Las estrategias para atenuar la gravedad de la mucositis oral secundaria a la terapia del $\mathrm{CCO}$ incluyen el mantenimiento de una higiene bucodental óptima y la implementación de protocolos de cuidado bucal. El enjuague frecuente de la boca con solución salina al 0,9\% o bicarbonato de sodio, el cepillado dental meticuloso y el hilado dental disminuyen la colonización bacteriana de las úlceras orales y acortan el tiempo de curación. Las prótesis 
dentales y los aparatos de ortodoncia mal ajustados que tienen el potencial de causar un trauma bucal deben ajustarse o retirarse ${ }^{6}$.

Es importante valorar el grado de severidad de la mucositis oral. Las escalas de medición más utilizadas son la recomendada por la OMS y la del Instituto Nacional del Cáncer de los Estados Unidos ( $\mathrm{NCl}$, por sus siglas en inglés). En 1979, la OMS definió el estado de las lesiones según la severidad compuesta de 5 grados de normal a severo, estableciendo así grados del 0 a 4. En 1998, el NCl presentó una actualización en la que se diferencia la mucositis debida a radiación, la mucositis debida a quimioterapia y la mucositis derivada del trasplante de médula ósea ${ }^{48}$. En la Tabla 6 , se describen ambas escalas, en el caso de la escala del $\mathrm{NCl}$ se muestran los criterios para la mucositis causada por quimioterapia y radioterapia.

Tabla 5. Productos comerciales sustitutos de saliva

\begin{tabular}{|l|l|l|l|}
\hline Producto & Componentes & Presentación & Dosificación \\
\hline $\begin{array}{l}\text { Kin Hidrat } \\
\text { (Laboratorio Kin) }\end{array}$ & $\begin{array}{l}\text { Xilitol 1\%, tiocinato potásico, cloruro potásico, cloruro sódico, } \\
\text { cloruro cálcico, cloruro magnésico, dihidrógeno fosfato } \\
\text { potásico, sacarina sódica, aceite de ricino hidrogenado, } \\
\text { metilparaben sódico, propilparaben sódico, bonoprol, mentol, } \\
\text { aroma, ácido cítrico, agua. }\end{array}$ & $\begin{array}{l}\text { Efectuar } 2 \text { o 3 } \\
\text { pulverizaciones en la } \\
\text { cavidad bucal con la } \\
\text { frecuencia que se considere } \\
\text { necesaria. }\end{array}$ \\
\hline $\begin{array}{l}\text { Dry Mouth Gel } \\
\text { (GC) } \\
\text { RECALDENT TM }\end{array}$ & $\begin{array}{l}\text { CPP-ACP (fosfopéptido de caseína-fosfato cálcico amorfo), } \\
\text { diglicerol, agua, carboximetilcelulosa de sodio, citrato de } \\
\text { sodio, sabor, etill p-hydroxibenzoato }\end{array}$ & Gel & $\begin{array}{l}\text { Aplicar el gel en mucosa } \\
\text { oral, lengua y dientes } \\
\text { con la frecuencia que se } \\
\text { considere necesaria }\end{array}$ \\
\hline $\begin{array}{l}\text { Moi-Stir Oral Spray } \\
\text { (Kingswood } \\
\text { Laboratories) }\end{array}$ & $\begin{array}{l}\text { Agua, sorbitol, carboximetilcelulosa de sodio, metilparabeno, } \\
\text { propilparabeno, cloruro de potasio, cloruro de sodio, } \\
\text { aromatizante }\end{array}$ & Aerosol & $\begin{array}{l}\text { Aplicar el aerosol en } \\
\text { cavidad oral con la } \\
\text { frecuencia necesaria }\end{array}$ \\
\hline $\begin{array}{l}\text { Biotene Oralbalance } \\
\text { (GlaxoSmithKline) }\end{array}$ & $\begin{array}{l}\text { Glucosa oxidasa, lisozima, lactoferrina, hidroxietilcelulosa, } \\
\text { glicerato polihidrato }\end{array}$ & Gel & $\begin{array}{l}\text { Aplicar el gel a los tejidos } \\
\text { bucales a demanda }\end{array}$ \\
\hline
\end{tabular}

Fuente: elaboración propia basado en Wiseman ${ }^{32}$, Laboratorios KIN ${ }^{46}$ y GC Latinoamérica ${ }^{47}$.

Tabla 6. Escalas de valoración de la mucositis oral.

\begin{tabular}{|c|c|c|c|c|c|}
\hline Escala & Grado 0 & Grado 1 & Grado 2 & Grado 3 & Grado 4 \\
\hline OMS & Normalidad & $\begin{array}{l}\text { Eritema } \\
\text { generalizado. } \\
\text { Mucosa } \\
\text { enrojecida. } \\
\text { No dolor. } \\
\text { Voz normal. }\end{array}$ & $\begin{array}{l}\text { Eritema. } \\
\text { Úlceras poco } \\
\text { extensas. } \\
\text { Se mantiene la } \\
\text { deglución de } \\
\text { sólidos. Dolor } \\
\text { ligero. } \\
\end{array}$ & $\begin{array}{l}\text { Úlceras extensas. } \\
\text { Edema en encías. } \\
\text { Saliva espesa. } \\
\text { Se mantiene la capacidad } \\
\text { de deglutir líquido } \\
\text { Dolor. } \\
\text { Dificultad para hablar. }\end{array}$ & $\begin{array}{l}\text { Úlceras muy } \\
\text { extensas. } \\
\text { Sangrado. Infecciones. } \\
\text { No hay saliva. } \\
\text { Sin deglución } \\
\text { Soporte enteral o parenteral. } \\
\text { Dolor severo. }\end{array}$ \\
\hline $\begin{array}{c}\mathrm{NCl} \\
\text { (Etiología } \\
\text { Radioterapia) }\end{array}$ & Normalidad & $\begin{array}{l}\text { Eritema } \\
\text { mucoso }\end{array}$ & $\begin{array}{l}\text { Lesiones } \\
\text { pseudo- } \\
\text { membranosas } \\
\text { irregulares, } \\
\text { generalmente } \\
\text { de } 1,5 \mathrm{~cm} \text { de } \\
\text { diámetro y no } \\
\text { continuas. }\end{array}$ & $\begin{array}{l}\text { Lesiones } \\
\text { pseudo-membranosas } \\
\text { confluyentes, } \\
\text { generalmente } \\
\text { mayores de } \\
1,5 \mathrm{~cm} . \text { de diámetro. }\end{array}$ & $\begin{array}{l}\text { Necrosis o ulceraciones } \\
\text { profundas, puede incluir } \\
\text { sangrado no inducido } \\
\text { por traumas menores o } \\
\text { abrasiones. }\end{array}$ \\
\hline $\begin{array}{c}\mathrm{NCl} \\
\text { (Etiología } \\
\text { Quimioterapia }\end{array}$ & Normalidad & $\begin{array}{l}\text { Sin dolor, } \\
\text { úlceras, } \\
\text { eritema o } \\
\text { dolor leve en } \\
\text { ausencia de } \\
\text { lesiones. }\end{array}$ & $\begin{array}{l}\text { Dolor, eritema, } \\
\text { edema o úlceras, } \\
\text { pero puede } \\
\text { comer o tragar. }\end{array}$ & $\begin{array}{l}\text { Dolor, eritema, edema o } \\
\text { úlceras. } \\
\text { Requiere hidratación } \\
\text { intravenosa. }\end{array}$ & $\begin{array}{l}\text { Ulceración } \\
\text { severa, requiere } \\
\text { nutrición enteral o parenteral } \\
\text { o intubación profiláctica. }\end{array}$ \\
\hline
\end{tabular}

Fuente: elaboración propia basado en De la Torre et $a^{48}$. 
En casos leves de mucositis (grado 1 o 2 ) las soluciones de recubrimiento de la mucosa y los agentes anestésicos proporcionan cierto alivio, como productos con lidocaína y enjuagues con hidrocloruro de bencidamina ${ }^{39}$.

Las intervenciones farmacológicas utilizadas actualmente para la mucositis oral incluyen citoprotectores como la amifostina IV, factores de crecimiento celular como la palifermina, vitamina E, suplementos metabólicos, antibióticos, antimicrobianos, agentes lubrificantes, antiinflamatorios y terapia génica ${ }^{48}$. También son utilizadas otras terapias como la crioterapia ${ }^{6}$ y la terapia con láser de baja potencia ${ }^{48}$.

El control de los síntomas requiere una evaluación regular del dolor inicial, el avance y el dolor incidente. Se puede comenzar con el uso de analgésicos/anestésicos tópicos y analgésicos orales no opioides y se puede adicionar opioides fuertes a dosis efectiva más baja. Si el dolor persiste, se administra un aumento de opioides mientras se continúa con la administración tópica y medicamentos no opioides. Los medicamentos coadyuvantes forman parte integral del tratamiento del dolor, porque este síntoma en la mucositis tiene componentes nociceptivos y neuropáticos. Las mediaciones coadyuvantes más utilizadas son la gabapentina y los antidepresivos tricíclicos. El dolor oral incidental es particularmente común con la función (por ejemplo, comer, hablar, medicación oral) y la atención eficaz de esta tipología dolorosa incluye la dosificación tópica y analgésica antes de la función oral ${ }^{49}$. En la Figura 2, se resumen algunas alternativas para la terapia de la mucositis oral.

\section{Reconstrucción zonas anatómicas afectadas por el cáncer de cavidad oral}

La resección de un tumor primario en cavidad oral generalmente requiere de una cirugía reconstructiva para restaurar la función oral y la apariencia estética. Los métodos de reconstrucción generalmente siguen una "escalera reconstructiva", que comienza desde un injerto de piel hasta un colgajo libre microvascular. Las transferencias de tejido autólogo libre representan actualmente una de las técnicas más populares y confiables para la reconstrucción oral. Hay opciones de tejido libre disponibles; pero, actualmente, no existe un colgajo único que pueda resolver todo el espectro de defectos orales ${ }^{51}$. En la Tabla 7, se describen el tipo de intervención reconstructiva de acuerdo con la zona afectada.

\section{Utilización de prótesis maxilofaciales}

La prótesis maxilofacial es la rama de la prostodoncia que se ocupa de la restauración o reemplazo de estructuras estomatognáticas y craneofaciales, con prótesis que pueden o no ser removidas de forma regular o electiva ${ }^{52}$. La reconstrucción maxilofacial implica la implantación de sustitutos artificiales de estructuras intraorales y extraorales. Las prótesis maxilofaciales se fabrican principalmente con resina acrílica o silicona, según la estructura facial de la persona y son retenidas y soportadas por estructuras como implantes osteointegrados, la piel remanente con o sin adhesivo, cavidades corporales y dientes ${ }^{53}$.

Después de la resección maxilar, se ha demostrado que las prótesis maxilofaciales mejoran la función de la deglución y la función articulatoria; estas funciones, sin embargo, están influenciadas por factores como el tamaño del defecto y el historial de radioterapia. El tratamiento protésico en la región mandibular puede ser difícil debido a la pérdida de mucosa móvil en el piso de la boca, a la continuidad interrumpida de la mandíbula y a cambios en la 
dirección de la mandíbula hacia el lado afectado ${ }^{54}$.

Las prótesis maxilofaciales se pueden clasificar como restauradoras o complementarias y estas sustituyen la pérdida ósea o reparan las deformidades del contorno facial. Pueden ubicarse internamente dentro del tejido o externamente como prótesis orales, oculares o faciales. Las prótesis complementarias ayudan en el período pre, trans o postquirúrgico, o en sesiones de radioterapia ${ }^{53}$. En la Tabla 8, se presentan distintos tipos de prótesis maxilofaciales que favorecerán la masticación y deglución.

\section{Intervención del edema y la fibrosis tisular}

Para la intervención del edema y la fibrosis tisular es necesario para mantener el mejor rango de movimiento posible, así como la fuerza y la elasticidad muscular. Se recomienda empezar con los ejercicios de rehabilitación logopédica desde antes de dar inicio con el tratamiento con radioterapia, continuar durante y después de este. Además, suele ser necesario poner en práctica maniobras y movimientos para una deglución más segura y eficaz, en muchas ocasiones se hace necesario realizar modificaciones en la textura de los alimentos ${ }^{55}$.

La radioterapia en cabeza y cuello puede provocar fibrosis de los tejidos de la hipofaringe y el esófago cervical. Cuando es severa, la fibrosis puede resultar en constricción o estenosis, que a su vez pueden desencadenar a la disfagia. Existe consenso en que la formación de constricción o estenosis ocurre en una mediana de 4 a 6 meses después del tratamiento de radioterapia ${ }^{38}$.

Una vez que está establecida la disfagia es necesaria una intervención coordinada de una forma interdisciplinaria. Un nutricionista, un rehabilitador y un terapeuta del lenguaje pueden proporcionar el uso de suplementos alimenticios, sumado al tratamiento logopédico de la disfagia y además, la intervención de terapia física con el objetivo de mejorar la flexibilidad muscular ${ }^{55}$.

En el caso de la estenosis esofágica, una vez que se hace su diagnóstico, por medio endoscópico o por la deglución de bario modificado, se puede iniciar un tratamiento con dilatación esofágica. Se requieren múltiples dilataciones para la mayoría de los pacientes. La tasa de éxito varía, pero se ha informado que llega al $78 \%{ }^{38}$.

\section{Aporte Interdisciplinario de los Cuidados}

\section{Paliativos en la atención de las limitaciones}

funcionales de la masticación y deglución de las

personas con cáncer de cavidad oral avanzado

Las personas con $\mathrm{CCO}$ requieren ser atendidas por equipos interdisciplinarios en todas las etapas de la enfermedad, la evaluación y planificación debe involucrar odontólogos, prostodoncistas maxilofaciales, otorrinolaringólogos, cirujanos de cabeza y cuello, oncólogos radioterapeutas, médicos, terapeutas de lenguaje, psicólogos, profesionales en enfermería, nutricionistas, fisioterapeutas, farmacéuticos y trabajadores sociales, para que con todo el equipo se logre llevar a cabo el tratamiento de forma integral, interviniendo en complicaciones orales que se puedan presentar así como afectación en la deglución y masticación ${ }^{8,53}$.

Uno de los papeles claves en la intervención de la disfagia, es el del otorrinolaringólogo, dada su formación específica es el profesional más calificado para el estudio y comprensión de la anatomía y funcionamiento de la nasofaringe, orofaringe, hipofaringe y laringe. En función de los resultados del examen clínico e instrumental solicitará la valoración de otros profesionales y la realización de otras pruebas. Decidirá el tratamiento más adecuado, 
si se permite o no la alimentación vía oral o si es preciso una sonda nasogástrica o de gastrostomía endoscópica percutánea (sonda PEG) 55 .

Los fisioterapeutas participan también en el diagnóstico de la disfagia, evaluando la movilidad y tono de la musculatura orofacial, praxias bucolinguales y reflejos de protección, teniendo en cuenta la inervación de cada estructura, para luego con base en la evaluación clínica y los estudios complementarios, se plantee una estrategia de intervención con técnicas de compensación o de rehabilitación ${ }^{56}$. En la tabla 9, se presenta la evaluación realizada a los músculos inervados por pares craneales.

El terapeuta del lenguaje es importante en la intervención de las alteraciones deglutorias en personas con $\mathrm{CCO}$, con la finalidad de rehabilitar la alimentación vía oral mediante técnicas de rehabilitación y de compensación, para disminuir residuos orales o faríngeos y reducir las aspiraciones ${ }^{22}$. Existen diferentes técnicas de compensación y rehabilitación para la intervención de Terapia del Lenguaje en las limitaciones de la deglución ${ }^{56}$. Estas técnicas se describen en las Figuras 3 y 4.

De igual manera, los nutricionistas tienen un rol específico en asegurar el aporte hídrico y nutricional, implementando fórmulas específicas para la hidratación y la alimentación de personas con disfagia por medio de la adaptación de la textura de los líquidos y los alimentos sólidos con el objetivo de obtener una deglución eficaz y segura mediante la confección de una dieta adaptada a una persona con disfagia ${ }^{57}$.

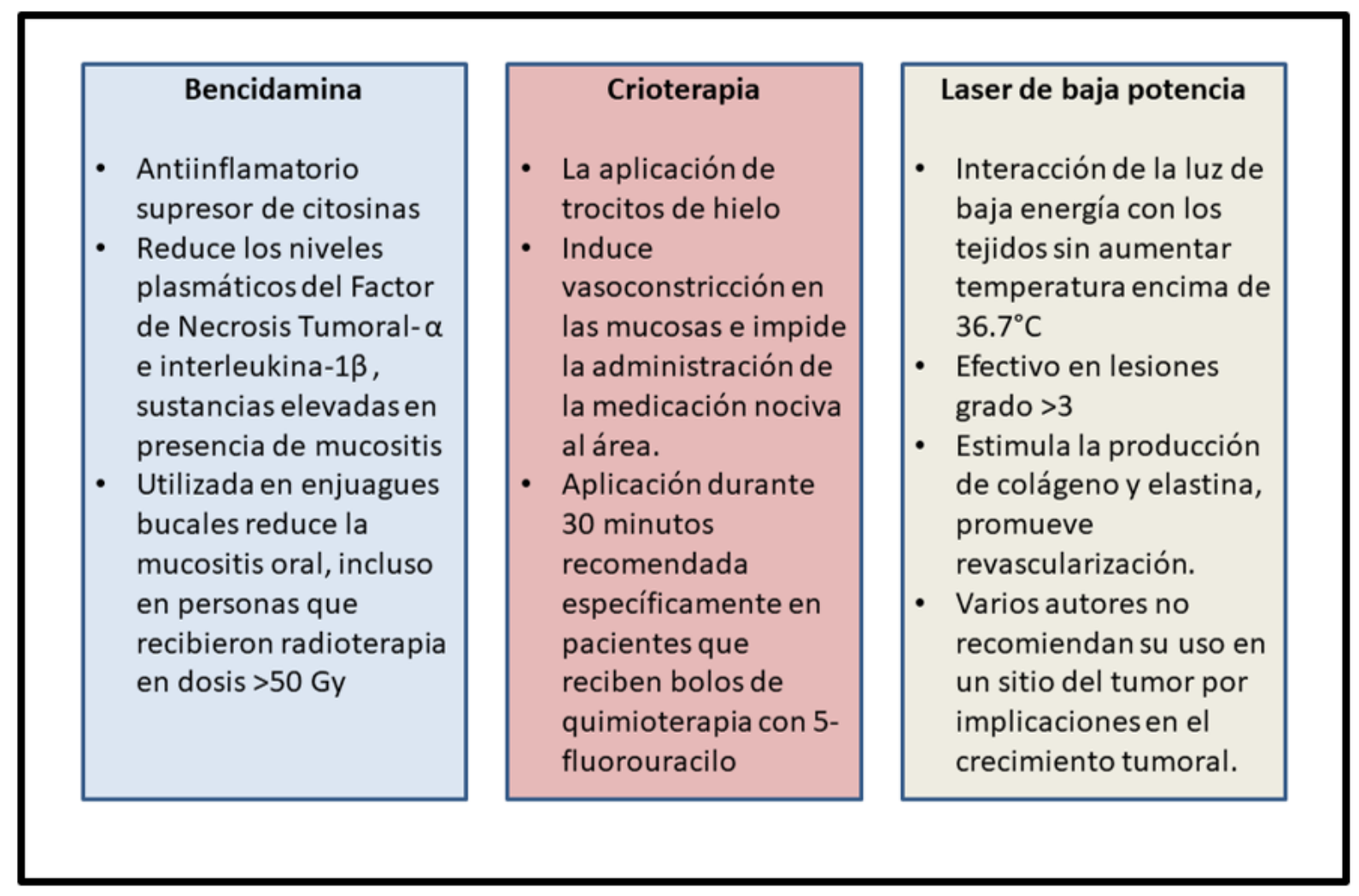

Figura 2. Alternativas utilizadas en la terapia de la mucositis oral.

Fuente: elaboración propia basada en referencias ${ }^{6,48-50}$ 


\section{Tabla 7. Intervención quirúrgica para la reconstrucción de zonas afectadas por el cáncer de cavidad oral}

\begin{tabular}{|c|c|}
\hline $\begin{array}{l}\text { Zona de la cavidad oral } \\
\text { afectada }\end{array}$ & Intervención quirúrgica reconstructiva \\
\hline Lengua & $\begin{array}{l}\text { - Los defectos de la hemiglosectomía se pueden reconstruir con un colgajo libre radial del antebrazo, } \\
\text { con funciones aceptables para el habla y la deglución. } \\
\text { - Los defectos de glosectomía subtotal o total pueden necesitar una reconstrucción convexa con un } \\
\text { colgajo libre anterolateral de muslo o recto abdominal. } \\
\text { - Cuando la resección se extiende a la base de la lengua puede ser necesario un colgajo de visera u } \\
\text { oscilación mandibular con liberación lingual mandibular para acceder a estas regiones. }\end{array}$ \\
\hline Piso de boca & $\begin{array}{l}\text { - Se puede reconstruir con un colgajo libre radial de antebrazo. } \\
\text { - Cuando la mandíbula se reseca segmentariamente, la reconstrucción se puede lograr con un colgajo } \\
\text { compuesto libre, como los colgajos osteocutáneos de peroné y osteocutáneo de escápula. } \\
\text { - En algunos casos de enfermedad avanzada, los defectos mandibulares pueden reconstruirse con una } \\
\text { placa de reconstrucción mandibular de titanio y los defectos de tejidos blandos pueden restaurarse con } \\
\text { un colgajo de recto abdominal libre que envuelve la placa de titanio. }\end{array}$ \\
\hline Mucosa bucal & $\begin{array}{l}\text { - Los defectos quirúrgicos se pueden cerrar primariamente en algunos casos; sin embargo, generalmente } \\
\text { se requiere un injerto de piel de espesor parcial o un injerto de mucosa para asegurar la apertura bucal. } \\
\text { - Los tumores bucales grandes requieren una intervención con colgajo de la mejilla en su parte inferior } \\
\text { y se extirpan junto con la grasa bucal y el maxilar o la mandíbula. } \\
\text { - El colgajo libre radial microvascular del antebrazo o un colgajo anterolateral de muslo se utilizan para } \\
\text { restaurar el grosor de la mejilla. }\end{array}$ \\
\hline Trígono retromolar & $\begin{array}{l}\text { Esta zona puede requerir consideraciones cuidadosas en la reconstrucción, los defectos pueden ser } \\
\text { extensos, muy complejos y ocasionalmente pueden causar trismus. En tales situaciones, los colgajos } \\
\text { libres dobles pueden proporcionar una reconstrucción ósea y de tejidos blandos ideales. }\end{array}$ \\
\hline $\begin{array}{l}\text { Gíngiva maxilar y paladar } \\
\text { duro }\end{array}$ & $\begin{array}{l}\text { - Los defectos quirúrgicos suelen restaurarse con una prótesis maxilar. } \\
\text { - En algunos casos, el cierre quirúrgico de los defectos se puede lograr con un colgajo local, como un } \\
\text { colgajo palatino y una almohadilla de grasa bucal. } \\
\text { - En tumores grandes, los defectos de tejidos blandos requieren un revestimiento con un injerto de piel } \\
\text { de espesor parcial para una buena restauración con una prótesis maxilar. }\end{array}$ \\
\hline Gíngiva mandibular & $\begin{array}{l}\text { - Cuando hay un defecto }>10 \mathrm{~mm} \text { en la mandíbula luego de la resección de la lesión, la mandíbula puede } \\
\text { reforzarse con una placa de titanio. } \\
\text { - Los defectos segmentarios de la mandíbula requieren la reconstrucción de la continuidad mandibular, } \\
\text { especialmente mediante el uso de un colgajo óseo vascularizado libre. } \\
\text { - La rehabilitación dental mediante una prótesis o implantes dentales osteointegrados es una parte } \\
\text { importante de la reconstrucción para restaurar la estética y las funciones. }\end{array}$ \\
\hline
\end{tabular}

Fuente: elaboración propia basado en Omura ${ }^{51}$. 


\section{Tabla 8. Prótesis maxilofaciales que favorecen las funciones de masticación y deglución}

\begin{tabular}{|c|c|}
\hline $\begin{array}{l}\text { Tipo de prótesis } \\
\text { maxilofacial }\end{array}$ & Funciones y características \\
\hline $\begin{array}{l}\text { Prótesis de } \\
\text { obturador } \\
\text { palatino }\end{array}$ & $\begin{array}{l}\text { - Se fabrican para cerrar las comunicaciones uni o bilaterales entre las cavidades oral y nasal, restaurar el habla, } \\
\text { mejorar la masticación y la deglución. } \\
\text { - Pueden fabricarse antes de la cirugía y aplicarse inmediatamente después para proteger la cavidad quirúrgica. } \\
\text { - Puede ser temporal, fabricado pocas semanas después de la cirugía, lo que permite tiempo para la } \\
\text { personalización y reparación del tejido. } \\
\text { - Las prótesis restaurativas o definitivas se fabrican después de la cicatrización. } \\
\text { - Tienen todas las características de las prótesis dentales convencionales, son más funcionales y dan como } \\
\text { resultado una mejor estética. }\end{array}$ \\
\hline $\begin{array}{l}\text { Prótesis de } \\
\text { lengua }\end{array}$ & $\begin{array}{l}\text { - La fabricación de una lengua artificial con inclinación posterior, para guiar el bolo alimenticio a la orofaringe } \\
\text { y una elevación anterior, para la articulación de fonemas y vocales dentilingües, mejora la capacidad de la } \\
\text { persona para masticar, tragar y hablar. } \\
\text { - Es prudente derivar al paciente a un terapeuta del lenguaje antes, durante y después del tratamiento para } \\
\text { mejorar su habla y aumentar el tono de los músculos circundantes para ayudar con las funciones orales. }\end{array}$ \\
\hline Prótesis labiales & $\begin{array}{l}\text { - Las prótesis labiales sellan los labios y restablecen el soporte de estos, para garantizar una mejor } \\
\text { masticación, deglución y habla. } \\
\text { - Además, restauran la apariencia, lo que mejora la autoestima y la calidad de vida. }\end{array}$ \\
\hline $\begin{array}{l}\text { Prótesis de } \\
\text { radioterapia }\end{array}$ & $\begin{array}{l}\text { - Estas prótesis, también conocidas como aparatos de soporte para la radiación, permiten orientar los elementos } \\
\text { radiactivos para tratar el tumor, atenuando las dosis absorbidas por los tejidos sanos adyacentes y así minimizan } \\
\text { las complicaciones funcionales posteriores. } \\
\text { - Estas prótesis se pueden realizar con resina o silicona y su fabricación implica un equipo de especialistas } \\
\text { integrados: un radioterapeuta, un físico y un odontólogo protésico. }\end{array}$ \\
\hline
\end{tabular}

Fuente: elaboración propia basada en de Caxias et $a^{53}$.

\section{Tabla 9. Evaluación de los músculos inervados por pares craneales en personas con disfagia orofaríngea.}

\begin{tabular}{|c|c|}
\hline Músculos & Forma de Evaluación \\
\hline Músculos de la boca & $\begin{array}{l}\text { - Se evalúa el cierre de los labios (orbicular de los labios) } \\
\text { - Compresión de la mejilla (buccinador) }\end{array}$ \\
\hline $\begin{array}{l}\text { Músculos de la } \\
\text { masticación }\end{array}$ & $\begin{array}{l}\text { - Apertura de la boca (pterigoideo externo y músculos supra hioideos) } \\
\text { - } \quad \text { Cierre de la boca (masetero, temporal y pterigoideo interno) } \\
\text { - } \quad \text { Pesplazamiento lateral de la mandíbula (pterigoideos externos e internos) } \\
\text { - Protrusión de la mandíbula (pterigoideos internos y externos) }\end{array}$ \\
\hline Músculos de la lengua & $\begin{array}{l}\text { - Observación de la lengua en reposo, y sobre el piso de la boca. } \\
\text { - Protrusión (geniogloso, fibras posteriores). } \\
\text { - } \text { - Resviación de la lengua (geniogloso y otros músculos) } \\
\text { - Elevación de la lengua (geniogloso y estilogloso) } \\
\text { - Acanalamiento de la lengua (geniogloso y músculos intrínsecos) } \\
\text { - Punta o doblado de la lengua (lingual superior y lingual inferior) }\end{array}$ \\
\hline $\begin{array}{l}\text { Músculos del velo del } \\
\text { paladar }\end{array}$ & $\begin{array}{l}\text { - Elevación y aducción del paladar blando (peristafilino interno, peristafilino externo, palatogloso y } \\
\text { ácigos de la úvula) }\end{array}$ \\
\hline Músculos de la faringe & $\begin{array}{l}\text { - Contracción durante la fonación (a-a-ah) y la elevación de la laringe durante la deglución. } \\
\text { - Provocar el reflejo faríngeo y comprobar la contracción muscular. }\end{array}$ \\
\hline Músculos de la laringe & $\begin{array}{l}\text { - Evaluación de la laringe durante la deglución para determinar si existe elevación de la laringe y su } \\
\text { extensión. }\end{array}$ \\
\hline
\end{tabular}

Fuente: elaboración propia basada en Campora et $\mathrm{al}^{20}$. 


\section{Cambios posturales}

- Mentón elevado: verticalización de la lengua y horizontalización de la epiglotis.

- Mentón flexionado pegado al tórax: coloca epiglotis hacia atrás y protege la vía aérea.

- Rotación de cabeza hacia lado lesionado: utilizado en personas con disminución de cierre laríngeo.

- Inclinación de cabeza hacia lado no afectado: ayuda a la apertura del esfínter esofágico superior.

- Decúbito lateral: elimina gravedad sobre residuo faríngeo.

- Flexión lateral de la columna cervical hacia lado no lesionado: controla mejor el bolo.

\section{Modificación del volumen y velocidad de presentación del bolo}

En personas con debilidad en la deglución faríngea la compensación consiste en dar bolos más pequeños a una velocidad menor para disminuir riesgo de aspiración por acúmulo de comida en la faringe.

\section{Modificación de consistencia}

- Se pretende que el alimento sea homogéneo, jugoso y de fácil masticación, sin grumos ni espinas.

- Evitar las dobles texturas.

- Variar los alimentos para evitar la rutina.

- El terapeuta del lenguaje determina la consistencia del alimento de acuerdo al diagnóstico de estructuras dañadas.

\section{Figura 3. Técnicas de compensación para la intervención de la disfagia}

Fuente: elaboración propia basada en la Mora Umaña et $a^{56}$.

\section{Maniobras deglutorias}

- Deglución supraglótica: aguantar respiración, deglutir y toser con fuerza

- Deglución supersupraglótica: aguantar respiración con esfuerzo muscular, deglutir y toser con fuerza

- Deglución forzada: deglutir ejerciendo fuerza en la musculatura

- Maniobras Mendelssonhn: sostener elevación laríngea al deglutir.

- Maniobras de Masako: deglutir con la lengua entre los dientes.

\section{Ejercicios Específicos}

- Masajes para la hipotonía: presión circular sobre músculos de la masticación, masaje en cuello, hombros, músculo buccinador, labio, alrededor de la boca y mejillas.

- Ejercicios para la movilidad orofacial: en labios (protruirlos, estirar y encoger, mover a los lados, presionarlos), lengua (acariciar paladar, sacar la lengua, moverla en todas las direcciones y dentro y fuera de la boca) y mandíbula (abrir y cerrar la boca y bostezar.
Técnicas de Facilitación

- Estimulación térmica: intraoral y extraoral (frío para subir el tono en hipotonías y calor para relajar músculos.

- Ejercicios contra resistencia: para aumentar fuerza muscular, resistencia en los labios, de lengua y orbicular.

- Terapia miofuncional: se realiza en músculos masticatorios, buccinador y orbicular de la boca y depresor de los labios.

Figura 4. Técnicas de rehabilitación en la disfagia

Fuente: elaboración propia basada en la Mora Umaña et al ${ }^{56}$. 
El farmacéutico, da recomendaciones y brinda educación respecto a la administración racional y segura de los medicamentos, por las dificultades en la ingesta de cápsulas o comprimidos. Les recordará a los profesionales en enfermería, cuidadores y familiares la dificultad en la deglución que presenta el enfermo, tanto para la toma de agua como de medicación. Buscará presentaciones farmacéuticas que se puedan tragar sin riesgo, evitando comprimidos duros o que puedan resultar resbaladizos ${ }^{55}$.

El profesional en enfermería debe asegurarse de que la persona esté en un ambiente relajado a la hora de comer y bien posicionado. Se requiere un seguimiento cuidadoso de los cambios en el apetito del enfermo y las dificultades que experimenta al comer. El control regular del peso ayudará a garantizar que la ingesta nutricional sea adecuada, al igual que el mantenimiento de un registro de la ingesta de alimentos ${ }^{58}$.

El profesional en enfermería puede evaluar, además, "si el paciente puede hablar, si tiene tos voluntaria, si controla su propia saliva, si es capaz de manejar el movimiento de los labios, los aspectos respiratorios o si tiene o no voz húmeda"55. La esencia misma de la enfermería "se centra en cuidar a la persona en su totalidad y apoyar a la familia en situaciones difíciles" 59 .

Cuando la alimentación enteral por vía oral no es eficiente o supone un riesgo será necesaria utilizar una vía artificial mediante sondas $u$ ostomías. Cuando se prevé la necesidad de una vía de acceso para nutrición enteral a corto plazo (4-6 semanas), se utiliza una sonda nasogástrica y si la previsión es a más largo plazo una gastrostomía, que puede ser colocada radiológica, endoscópica o quirúrgicamente. La utilización de nutrición parenteral, es decir, la administración de nutrientes por medio de una vía venosa en las personas con disfagia es excepcional ${ }^{55}$.

\section{Conclusiones}

La odontología tiene relevancia en la intervención paliativa de las personas con CCO avanzado con limitaciones en la masticación y deglución al proporcionar un cuidado total y activo de la boca, en el que el alivio del dolor y el mantenimiento de las piezas dentales es una prioridad. A esto se le suma la intervención del trismus, principalmente mediante ejercicios de terapia física, el tratamiento de infecciones bucales, la prevención e intervención de la osteorradionecrosis, que son determinantes para optimizar la función masticatoria. El alivio de los efectos de la reducción del flujo salival utilizando agonistas colinérgicos y saliva artificial son útiles para mejorar la deglución.

Las estrategias utilizadas para intervenir la mucositis oral incluyen el mantenimiento de una higiene bucodental, los agentes anestésicos, enjuagues con hidrocloruro de bencidamina y alternativamente la terapia con láser de baja potencia y la crioterapia.

La cirugía reconstructiva o la sustitución de estructuras por medio de prótesis maxilofaciales para restaurar la función mejoran la calidad de vida. Finalmente, las personas con CCO avanzado requieren de atención interdisciplinaria, para que se pueda llevar a cabo la planificación de la atención en forma integral.

\section{Referencias Bibliográficas}

1. Mateo-Sidron Anton M, Somacarrera-Pérez M. Cáncer oral: Genética, prevención, diagnóstico y tratamiento. Revisión de la literatura. Av Odontoestomatol. 2015;31(4):247-59. doi: 10.4321/S021312852015000400002 
2. Ministerio de Salud (CR) [Internet]. San José: Ministerio de Salud. Estadística de Cáncer-Registro Nacional de Tumores; 2014. Disponible en: https:// www.ministeriodesalud.go.cr/index.php/vigilancia-de-la-salud/estadisticas-y-bases-de-datos/estadisticas/estadistica-de-cancer-registro-nacional-tumores

3. Moro S, Maroneze MC, Ardenghi TM, Barin LM, Danesi CC. Câncer de boca e orofaringe: epidemiologia e análise da sobrevida. Einstein (São Paulo). 2018;16(2):1-5. doi: 10.1590/s1679$45082018 a 04248$

4. Boing AF, Antunes JLF. Condições socioeconômicas e câncer de cabeça e pescoço: uma revisão sistemática de literatura. Cien Saude Colet. 2011;16(2):615-22. doi: 10.1590/S141381232011000200025

5. Stewart BW, Wild CP, editors. World cancer report 2014. Lyon: International Agency for Research on Cancer, World Health Organization; 2014.

6. Villa A, Akintoye SO. Dental management of patients who have undergone oral cancer therapy. Dent Clin North Am. 2018;62(1):131-42. doi: 10.1016/j.cden.2017.08.010

7. Bruera E, Higginson I, von Gunten CF, Morita T, editors. Textbook of Palliative Medecine and Supportive Care. 2nd ed. Florida: CRC Press; 2016.

8. Araya C. Diagnóstico precoz y prevención en cáncer de cavidad oral. Rev Médica Clínica Las Condes. 2018;29(4):411-8. doi: 10.1016/j.rmclc.2018.06.008

9. Silva D. Oral cancer: diagnosis, treatment and prevention. Dent Nurs. 2010;6(2):84-87. doi: 10.12968/denn.2010.6.2.46234

10. Rhodus NL, Kerr AR, Patel K. Oral Cancer. Leukoplakia, Premalignancy, and Squamous Cell Carcinoma. Dent Clin North Am. 2014;58(2):315-
40. doi: 10.1016/j.cden.2013.12.004

11. Moreno OL, Álvarez JA. Frecuencia de patologías orales malignas en la población de Popayán en el periodo enero de 2000 a octubre de 2006. Rev Fac Cienc Salud Univ Cauca [Internet]. 2007;9(2):15-21. Disponible en: https://dialnet.unirioja.es/descarga/articulo/6544663.pdf

12. Álvarez-Martínez E, Preciado-U A, Montoya-Fernández $S$, Jiménez-Gómez R, Posada A. Características clínico-histopatológicas del carcinoma escamocelular bucal, Colombia. Rev Cubana Estomatol [Internet].2010;47(1):81-95. Disponible en: http://scielo.sld.cu/pdf/est/v47n1/est07110.pdf

13. Saloura V, Langerman A, Rudra S, Chin $\mathrm{R}$, Cohen EEW. Multidisciplinary care of the patient with head and neck cancer. Surg Oncol Clin N Am. 2013;22(2):179-215. doi: 10.1016/j. soc.2012.12.001

14. Caputo JB, Campos SS, Pereira SM, Castelo PM, Gaviao MBD, Marques LS, et al. Masticatory performance and taste perception in patients submitted to cancer treatment. J Oral Rehabil. 2012;39:905-13. doi: 10.1111/joor.12005

15. Kolokythas A, Miloro M. Overview of complications of oral surgery. En: Epstein J, Davies A, editors. Oral Complications of Cancer and its Management. Oxford: OUP Oxford; 2010. 79-88.

16. Dijkstra P, Roodenburg J. Trismus. En: Epstein J, Davies A, editors. Oral Complications of Cancer and its Management. Oxford: OUP Oxford; 2010. 99-116.

17. Moon DH, Ho S, Wang K, Weissler MC, Hackman TG, Zanation AM, et al. Incidence of, and risk factors for, mandibular osteoradionecrosis in patients with oral cavity and oropharynx cancers. Oral Oncol. 2017;72:98-103. doi: 10.1016/j.oraloncology.2017.07.014 
18. Spijkervet F, Vissink A. Post-radiation osteonecrosis (osteoradionecrosis) of the jaws. En: Epstein J, Davies A, editors. Oral Complications of Cancer and its Management. Oxford: OUP Oxford; 2010. 9-14.

19. Sonis S, Treister N. Oral mucositis. En: Epstein J, Davies A, editors. Oral Complications of Cancer and its Management. Oxford: OUP Oxford; 2010. 141-9.

20. Campora H, Falduti A. Evaluación y tratamiento de las alteraciones de la deglución. Rev Am Med Respir [Internet]. 2012;3:98-107. Disponible en: https://www.redalyc.org/pdf/3821/382138394004. pdf

21. Nemeth D, Zaleczna L, Huremovic A, Engelmann J, Poeschl PW, Strasz M, et al. Importance of chewing, saliva, and swallowing function in patients with advanced oral cancer undergoing preoperative chemoradiotherapy: a prospective study of quality of life. Int J Oral Maxillofac Surg. 2017;46(10):1229_ 36. doi: 10.1016/j.ijom.2017.05.005

22. Galarza-Ibarrondo I, Ortiz-Fernández L, Andikoetxea-Agorria B. Tratamiento de la disfagia y la disglosia tras glosectomía total y reconstrucción con colgajo libre fasciocutáneo anterolateral de muslo: A propósito de un caso. Rev Logop Foniatr y Audiol. 2014;34(4):185-90. doi: 10.1016/j.rlfa.2013.11.003

23. Zuydam AC, Lowe D, Brown JS, Vaughan ED, Rogers SN. Predictors of speech and swallowing function following primary surgery for oral and oropharyngeal cancer. Clin Otolaryngol. 2005;30(5):428-37. doi: 10.1111/j.13652273.2005.01061.x.

24. Halczy-Kowalik L, Wiktor A, Rzewuska A, Kowalczyk R, Wysocki R, Posio V. Compensatory Mechanisms in Patients After a Partial or Total Glossectomy due to Oral Cancer. Dysphagia. 2015;30(6):738-50. doi: 10.1007/s00455-0159652-z.
25. Jiménez C, Corregidor Al, Gutiérrez C. Disfagia. En: Tratado de Geriatría para Residentes. Madrid: Sociedad Española de Geriatría y Gerontología; 2006. 545-53

26. Chi AC, Day TA, Neville BW. Oral cavity and oropharyngeal squamous cell carcinoma-an update. CA Cancer J Clin. 2015;65(5):401-21. doi: 10.3322/ caac. 21293.

27. Khandelwal A, Neeli A, Gadiyar A, Khandelwal A. Assessment of Quality of Life of Patients 1-5 Years after Treatment for Oral Cancer. Indian J Dent Res. 2017;28(5):538-544. doi: 10.4103/ijdr. IJDR_97_17

28. Pierre CS, Dassonville O, Chamorey E, Poissonnet G, Riss JC, Ettaiche M, et al. Longterm functional outcomes and quality of life after oncologic surgery and microvascular reconstruction in patients with oral or oropharyngeal cancer. Acta Otolaryngol. 2014;134(10):1086-93. doi: 10.3109/00016489.2014.913809

29. Presswood E, Noble S. Palliative medicine: medical and psychological aspects. Surg (United Kingdom). 2017;36(3):117-21. doi: 10.1016/j.mpsur.2017.12.009

30. Allen S, Lowe D, Harris R V., Brown S, Rogers $\mathrm{SN}$. Is social inequality related to different patient concerns in routine oral cancer follow-up clinics? Eur Arch Oto-Rhino-Laryngology. 2017;274(1):4519. doi: 10.1007/s00405-016-4208-x

31. Moore KA, Ford PJ, Farah C. Support needs and quality of life in oral cancer: a systematic review. Int J Dent Hyg. 2014;12(1):36-47. doi: 10.1111/ idh. 12051

32. Wiseman M. Palliative Care Dentistry: Focusing on Quality of Life. Compend Contin Educ Dent. 2017;38(8):529-34.

33. Li L, Sloan DH, Mehta AK, Willis G, Weaver 
MS, Berger AC. Life perceptions of patients receiving palliative care and experiencing psycho-social-spiritual healing. Ann Palliat Med. 2017l;6(3):211-219. doi: 10.21037/apm.2017.05.03.

34. Davies AN. Oral care. En: Cherny N, FaIlon M, Kaasa S, Portenoy RK, Currow DC, editors. Oxford Medicine Online Oxford Textbook of Palliative Medicine. 5th ed. Oxford University Press; 2015. 1-33.

35. Thanvi J, Bumb D. Dental agony of oral cancer patients. J Indian Dent Assoc [Internet]. 2014;8(6):32-7. Disponible en: http://publication. ida.org.in/IndexMain.htm\#/viewArticle/8104

36. Alfaro-Moctezuma $\mathrm{P}$, Ángeles-Medina $\mathrm{F}$, Osorno-Escareño MC, Núñez-Martínez J, Romero-Esquiliano G. Fuerza de mordida: su importancia en la masticación, su medición y sus condicionantes clínicos. Parte II. Rev ADM [Internet]. 2012;69(3):108-13. Disponible en: https://www.medigraphic.com/pdfs/adm/od-2012/od123c.pdf

37. Quirós-Delgado A, Úcles V. Trismus: un reto en la rehabilitación oncológica. Rev Clin Esc Med UCR [Internet]. 2016;6(3):1-6. Disponible en: https://www.medigraphic.com/pdfs/revcliescmed/ucr2016/ucr163d.pdf

38. Murphy BA, Gilbert J. Oral cancers: supportive care issues. Periodontol 2000. 2011;57(1):11831. doi: 10.1111/j.1600-0757.2011.00394.x

39. Brody S, Omer O, McLoughlin J, Stassen L. The dentist' $s$ role within the multi-disciplinary team maintaining quality of life for oral cancer patients in light of recent advances in radiotherapy. J Irish Dent Assoc [Internet]. 2013;59(3):137-146. Disponible en: https://www.lenus.ie/bitstream/handle/10147/294482/No3\%20-June\%20Julyart1-2ART. pdf?sequence=1\&isAllowed=y

40. Satheeshkumar PS, Mohan MP, Jacob J. Restricted mouth opening and trismus in oral oncology. Oral Surg Oral Med Oral Pathol Oral Radiol. 2014;117(6):709-15. doi: 10.1016/j. oooo.2014.02.031

41. Mulk BS, Chintamaneni RL, Prabhat M, Gummadapu S, Salvadhi SS. Palliative dental care- A boon for debilitating. J Clin Diagn Res. 2014;8(6):16. doi: 10.7860/JCDR/2014/8898.4427

42. Rudy Hernán GL. Manejo del dolor en cáncer. Rev Méd Clín Las Condes. 2013; 24(4):661-6. doi: 10.1016/S0716-8640(13)70205-0

43. Lanza-Echeveste D. Tratamiento odontológico integral del paciente oncológico: parte II. Odontoestomatol [Internet]. 2013;15(22):46-63. Disponible en: http://www.scielo.edu.uy/pdf/ode/v15n22/ v15n22a06.pdf

44. Lai T, Wang T, Liu C, Chao T, Chen T, Hu Y. Risk factors for osteonecrosis of the jaw in oral cancer patients after surgery and eventual adjuvant treatment: The potential role of chemotherapy. Radiother Oncol. 2017;123(3):406-11. doi: 10.1016/j. radonc.2017.05.001

45. Mulk B, Chintamaneni R, Mpv P, Gummadapu S, Salvadhi S. Palliative Dental Care - A Boon for Debilitating. J Clin Diagn Res. 2014;8(6):1-7. doi: 10.7860/JCDR/2014/8898.4427

46. Laboratorios KIN. KIN [Internet]. Barcelona: Laboratorios KIN; 2021. KIN Hidrat Spray Bucal; [aprox 1 pantalla]. Disponible en: https://www.kin.es/ producto/kin-hidrat-spray-bucal/

47. GC Latinoamérica [Internet]. GC Latinoamérica; 2021. Dry Mouth Gel; [aprox. 1 pantalla]. Disponible en: http://gclatinamerica.com/descripcion/12

48. De La Torre F, Alfaro C. Terapia de laser de baja potencia en mucositis oral. Rev Estomatol Hered. 2016;26(1):47-55. doi: 10.20453/reh.v26i1.2820

49. Barasch A, Epstein JB. Management of cancer therapy-induced oral mucositis. Derma- 
tol Ther. 2011;24(4):424-31. doi: 10.1111/j.15298019.2011.01434.x

50. Rastogi M, Khurana R, Revannasiddaiah S, Jaiswal I, Nanda SS, Gupta P, et al. Role of benzydamine hydrochloride in the prevention of oral mucositis in head and neck cancer patients treated with radiotherapy (>50 Gy) with or without chemotherapy. Support Care Cancer. 2017;25(5):1439-43. doi: 10.1007/s00520-016-3548-9

51. Omura K. Current status of oral cancer treatment strategies: Surgical treatments for oral squamous cell carcinoma. Int J Clin Oncol. 2014;19(3):423-30. doi: 10.1007/s10147-0140689-z

52. Dudley J, Mughal F, Hotinski E, Mahmud M. Prosthodontic management of maxillofacial cases: a case series. Aust Dent J. 2018;63(1):124-8. doi: 10.1111/adj.12563

53. de Caxias FP, dos Santos DM, Bannwart LC, de Moraes Melo Neto CL, Goiato MC. Classification, history, and future prospects of maxillofacial prosthesis. Int J Dent. 2019;2019:8657619. doi: 10.1155/2019/8657619.

54. Hagio M, Ishizaki K, Ryu M, Nomura T, Takano N, Sakurai K. Maxillofacial prosthetic treatment factors affecting oral health-related quality of life after surgery for patients with oral cancer. J Prosthet Dent. 2018;119(4):663-670. doi: 10.1016/j.prosdent.2017.05.017.

55. Rodríguez-Acevedo $\mathrm{M}$, Vaamonte Lago P, González-Paz T, Quintana-Sanjuás A, González-Cortés M. Disfagia Orofaríngea: Actualización y manejo en poblaciones específicas [Internet]. España: Sociedad Gallega de Otorrinolaringología y Patología Cérvico-Facial; 2018. Disponible en: http:// www.sgorl.org/images/Ponencias/DISFAGIA_OROFARÍNGEA_ACTUALIZACIÓN_Y_MANEJO_EN_ POBLACIONES_ESPECÍFICAS.pdf
56. Mora-Umaña I, Alvarado-Murillo A, López-Torres C, Solano-Rojas C. Intervención de la terapia del lenguaje en las alteraciones deglutorias y de la voz en pacientes con cáncer de cabeza y cuello. Rev Ter. 2020;14(2):56-70. doi: 10.33967/rt.v14i2.114

57. Calleja-Fernández A, Pintor de la Maza B, Vidal-Casariego A, Villar-Taibo R, Urioste-Fondo A, Cano-Rodríguez I, et al. Características técnicas de los productos alimentarios específicos para el paciente con disfagia. Nutr Hosp. 2015;32(4):1401-7. doi: 10.3305/nh.2015.32.4.9528

58. Morris $H$. Dysphagia in the elderly -a Management Challenge for Nurses. $\mathrm{Br}$ J Nurs. 2006;15(10):558-62. doi: 10.12968/ bjon.2006.15.10.21132.

59. Fitch MI, Fliedner MC, O'Connor M. Nursing perspectives on palliative care 2015. Ann Palliat Med. 2015;4(3):150-5. doi: 10.3978/j.issn.22245820.2015 .07 .04 